\title{
Vapors in the ambient-A complication in tribological studies or an engineering solution of tribological problems?
}

\author{
Ala ALAZIZI, Anthony J. BARTHEL, Nicholas D. SURDYKA, Jiawei LUO, Seong H. KIM* \\ Department of Chemical Engineering and Materials Research Institute, Pennsylvania State University, University Park, PA 16802, USA \\ Received: 04 February 2015 / Revised: 14 April 2015 / Accepted: 15 May 2015 \\ (C) The author(s) 2015. This article is published with open access at Springerlink.com
}

\begin{abstract}
Tribology involves not only two-body contacts of two solid materials-a substrate and a counter-surface; it often involves three-body contacts whether the third body is intentionally introduced or inevitably added during the sliding or rubbing. The intentionally added third body could be lubricant oil or engineered nanomaterial used to mitigate the friction and wear of the sliding contact. The inevitably added third body could be wear debris created from the substrate or the counter surface during sliding. Even in the absence of any solid third-body between the sliding surfaces, molecular adsorption of water or organic vapors from the surrounding environment can dramatically alter the friction and wear behavior of solid surfaces tested in the absence of lubricant oils. This review article covers the last case: the effects of molecular adsorption on sliding solid surfaces both inevitably occurring due to the ambient test and intentionally introduced as a solution for engineering problems. We will review how adsorbed molecules can change the course of wear and friction, as well as the mechanical and chemical behavior, of a wide range of materials under sliding conditions.
\end{abstract}

Keywords: vapor phase lubrication; environmental effect

\section{Introduction}

The adsorption of molecules on solid surfaces from the gaseous environment is inevitable unless the solid surface is inert or has extremely low surface energy $[1,2]$. The chemistry of the molecular impingement, adsorption, and reaction on solid surfaces is the core of gas separation and catalysis. Considerable research has been conducted focusing on improving adsorption or reaction selectivity and understanding adsorption behavior in heterogeneous catalysis [3]. This is especially true for nano-scale catalyst particles [4] and porous solids such as metal-organic frameworks (MOFs) and zeolites [5,6]. Poisoning or deactivation of catalyst adsorption sites by an undesired reaction product or trace contaminant can quickly render the catalyst useless [7]. Gas phase chemical sensors and detectors also depend on the process of gas and vapor adsorp-

*Corresponding author: Seong H. KIM.

E-mail: shkim@engr.psu.edu tion. This field has seen tremendous growth with research focusing on new detection methods, increased sensor selectivity and robustness, and expanded contaminant tolerance. Many good review articles cover both commercialized sensors as well as current areas of research [8-12].

Although invisible thus often ignored, the same processes of gas impingement, adsorption, and reaction at the solid surface play critical roles in tribology too. For example, the effects of oxygen or humidity on tribological measurements have long been recognized and documented in the literature. Adsorbed vapors can be essential for super-lubricious behavior [13] or they can deteriorate lubricity [14]. They can prevent wear [15] or result in catastrophic adhesive wear and tribochemical reactions [16]. Adsorbed vapors also play a crucial role in nano-scale contact by controlling adhesion and interfacial shear $[17,18]$.

This article will give an overview of the environmental effects on tribology focusing on the influence of adsorbed molecules on friction, wear, and surface 
structure of metals, ceramics, glasses, oxides, carbon materials, and polymers. The effect of surface roughness on vapor-phase lubrication will then be discussed. That will be followed by a section investigating the application of vapor phase lubrication in the lubrication of microelectromechanical system (MEMS) and in mechanochemical synthesis from adsorbed vapors under sliding contact.

\section{Environmental effect on tribological and interfacial properties of materials}

Macro-scale tribological tests with controlled vapor environments primarily rely on two test methods to determine the behavior of friction and wear. These are fretting and ball-on-flat tests. Other important test methods, such as the four-ball test often used for liquid lubricants [19], are generally less common for vapor tests. In a fretting test, two bodies in contact undergo a periodic oscillatory displacement with high frequency to simulate intermittent or unintended contact between unlubricated surfaces [20]. Ball-on-flat tests, also called pin-on-disk or pin-on-flat, consist of a spherical ball in contact with a flat counter-surface. Ball-on-flat tests can be conducted in a bi-directional mode during which the ball reverses direction along the wear track, or in a continuous mode conducted on a revolving disk.

\subsection{Environmental effect on friction and wear of metals}

Metals are perhaps the most extensively studied class of tribological materials because of their wide usages in diverse industries. Thus, a considerable portion of the literature is concerned with oil lubrication on industrially relevant alloys. The fundamental problem of the effect of environmental vapors on tribology of metals, which gets less attention, generally concentrates on pure metals. Therefore, the extent to which one or a few physisorbed molecular layers can change friction and wear across length scales has not been fully appreciated. This can be seen in tribology test reports that state the test conditions to be "humid" without measuring the humidity, or tests that simply state "air" without investigating the amount or type of vapors that may adsorb. Even tests that investigate friction and wear on metals in a vapor environment frequently do not give mechanistic explanations for observed results.

The effect of water vapor on tribological performances of steels is a commonly studied subject. Initial fretting tests showed mixed results; some reported the largest wear in dry air and a monotonic decrease with increasing relative humidity (RH) [21], while others showed maximum wear at intermediate $\mathrm{RH}$ [22]. Unfortunately many investigations did not attempt to explain the trends that were found, but those that did often reported the formation of an oxide layer to be a prominent factor affecting friction and wear of steel.

The majority of recent literature on steels generally agrees that increased $\mathrm{RH}$ causes a decrease in wear. The friction and wear of mild and carbon steels were shown to decrease with increasing $\mathrm{RH}$ in pin-on-disk experiments when tested over the range of $60 \%-80 \%$ $\mathrm{RH}$, although lower $\mathrm{RH}$ values were not investigated and mechanism was not reported [23, 24]. Pin-on-disk studies between carbon steels with varying carbon contents found a transition from severe wear to mild wear at intermediate RH (40\%-50\%), with mild wear being attributed to shear occurring on a surface oxide layer [25]. The same trend was observed in pin-on-disk tests using AISI 304 stainless steel [26, 27]. It was reported that increased wear at lower $\mathrm{RH}$ was due to the formation of more oxidized wear particles which caused abrasive wear [27]. Fretting tests with carbon steel, however, reported that the presence of oxygen had a much stronger influence on wear than water vapor in tests conducted in wet argon and air [28]. Water vapor itself had a negligible effect on wear at $50 \%-80 \%$ RH [28]. Figure 1 depicts the wear measurements for AISI 304 steel in 20\%, 50\%, and $80 \% \mathrm{RH}$, and many figures describing steel wear in the literature are in a similar fashion. Both steels tested exhibit a decrease in wear more than half as humidity increased from $20 \%$ to $80 \%$ [27].

The water vapor in air has also been shown to act as a coolant and lubricant in cutting tool operations with AISI 304 stainless steel [29]. Oxidation was purported to be the cause, although tests in pure oxygen did not show the same wear reduction. Oxidation is an important mechanism in bearing steel tests as well. Severe wear was found in pin-on-disk tests below $15 \% \mathrm{RH}$ and the lowest amount of wear was seen near 


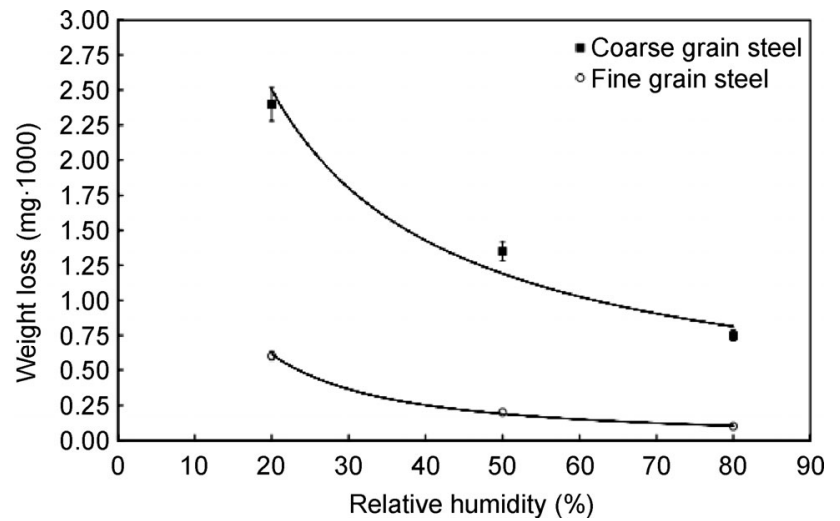

Fig. 1 Relationship between weight loss (wear) and RH for AISI 304 stainless steel samples of different grain size in a pin-on-disc tribometer with a sliding velocity of $10 \mathrm{~cm} / \mathrm{s}$, load of $2 \mathrm{~N}$ and average contact pressure of $358 \mathrm{MPa}$. Reproduced with permission from Ref. [27]. Copyright Springer, 2004.

$100 \%$ RH [30]. Similarly, fretting tests on bearing steel showed lower friction and wear and less material transfer as RH increased [31]. This decrease in adhesion between the contacting surfaces was ascribed to the tribochemical formation of surface hydroxides and hydrates.

Adsorbed vapors can affect friction and wear through tribochemical reactions at the sliding interfaces. For example, adsorbed water vapor at high relative humidity results in electrochemical reactions between dissimilar metals such as AISI 440C stainless steel and copper. Figure 2 shows the change in the wear pattern of a copper substrate when sliding using 440C stainless steel ball occurs at increasing humidity [16]. While dry sliding resulted in a plastic deformation in copper along with mild abrasive wear (Fig. 2(a)), sliding at intermediate humidity produced severe adhesive wear with deep trenches and tall pile-ups on the copper substrate (Fig. 2(b)). On the other hand, friction tests at high $\mathrm{RH}(>80 \%)$ produced ironcontaining wear debris on the copper surface (Fig. 2(c)) indicating that the hard stainless steel was worn and the soft copper was intact [16]. This is because, after the corrosion-resistant chromium oxide layer on stainless steel was damaged during sliding, the thick layer of adsorbed water acted as an electrolyte solution allowing the steel alloy to undergo galvanic corrosion.

Friction and wear tests of aluminum alloys in humid environments generally report that the formation and adherence of wear debris are the most influential mechanism for wear. However, agreement on the role of $\mathrm{RH}$ in this process is not universal. Fretting tests of the alloy 7075 aluminum found that friction as well as wear decrease as $\mathrm{RH}$ increases in the range of $10 \%-$ $90 \% \mathrm{RH}$ [33]. The mechanism responsible for this was described as tribo-oxidation which produced alumina and helped lubricate the sliding contacts. Pin-on-disk tests using nearly atomically pure aluminum found similar results in that alumina forms more readily and that wear debris size is smaller and contains more oxygen with increasing RH [34]. However, although wear decreased with increasing $\mathrm{RH}$, no effect on friction was observed. Wear was also shown to decrease at very high $\mathrm{RH}$ for an $\mathrm{Al}-\mathrm{Si}$ eutectic alloy where oxidative wear formed oxide-rich film at $95 \% \mathrm{RH}$ preventing direct contact between sliding surfaces $[35,36]$. Other tests found friction and wear to increase with increasing $\mathrm{RH}$, although this was also said to be caused by the formation and adhesion of oxide debris particles. Fretting tests with an $\mathrm{Al}-\mathrm{Zn}-\mathrm{Mg}$ alloy found wear to increase with increasing $\mathrm{RH}$ due to the lack of adhered debris [37]. Similarly, pin-on-disk tests using BS1474 aluminum found an increase in wear as RH increased from $20 \%$ to $80 \%$ [38]. More debris was found on the
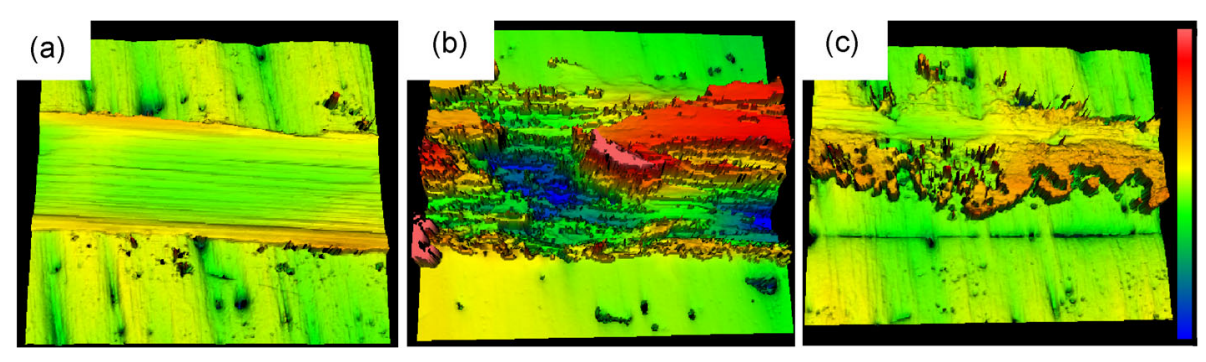

Fig. 2 Wear profile (taken with an optical profilometer) of polished flat copper substrate after rubbing against 440C stainless steel ball in (a) dry nitrogen, (b) $40 \% \mathrm{RH}$, and (c) $90 \% \mathrm{RH}$ in a pin-on-disk tribometer operating at $2 \mathrm{~mm} / \mathrm{s}, 1 \mathrm{~N}$ normal load and average contact pressure of $325 \mathrm{MPa}$. The scale bar at right goes from $\pm 0.5 \mu \mathrm{m}$ for (a) and (c) and $\pm 2 \mu \mathrm{m}$ for (b). Reproduced with permission from Ref. [32]. Copyright Maney Online, 2012. 
pin at lower $\mathrm{RH}$ and the higher wear was attributed to debris egress.

Water vapor on other metals generally shows the trend of increased wear at low humidity. Fretting tests of tin observed lower wear at high $\mathrm{RH}$, as did pin-ondisk tests $[39,40]$. Experiments investigating the fretting wear of many pure metals, including $\mathrm{Ti}, \mathrm{Al}, \mathrm{Ag}$, and $\mathrm{Cu}$, found that most metals experience a maximum in wear at a moderately low humidity, but that the wear maximum does not occur at the absolute minimum humidity tested [41]. Nearly all metal tests report continuously increasing or decreasing wear as $\mathrm{RH}$ increases, and this non-monotonic behavior of wear with respect to RH has not been widely observed in other experiments. In a case of debris-influenced wear behavior, brass wear in fretting tests was seen to increase with increasing $\mathrm{RH}$ due to additional egress of the debris material [42].

Water vapor was found to partially dissociate and form relatively stable $\mathrm{H}_{2} \mathrm{O}-\mathrm{OH}$ complexes at the surface of $\mathrm{Cu}$ at near ambient water vapor pressure and from 275-520 K [43]. The stability of this $\mathrm{H}_{2} \mathrm{O}-\mathrm{OH}$ complex was found to lower the desorption kinetics for $\mathrm{H}_{2} \mathrm{O}$ significantly and facilitate the reaction with atomic $\mathrm{O}$ on the $\mathrm{Cu}$ surface [43]. Similar studies have been conducted on copper oxide and aluminum oxide. These studies found that adsorbed water will react with lattice oxygen to form $\mathrm{OH}$ and that this reaction is completed by $\sim 1 \% \mathrm{RH}$ [44]. Increasing $\mathrm{RH}$ beyond this point results in an adsorbed water layer that reaches a monolayer near $15 \% \mathrm{RH}$ and about 6 layers at $90 \% \mathrm{RH}$ [44]. Additional adsorbing species can greatly complicate the surface reactions. Coadsorption of water and carbon dioxide onto $\mathrm{Cu}$ formed hydroxyl, formate, and methoxy species with $\mathrm{H}_{2} \mathrm{O}$ providing the hydrogen $[45,46]$. In addition to reactions with other species, dissociation of water is important as molecular hydrogen has been shown to make steel more brittle and prone to fracture [47]. All of these surface adsorption studies were conducted in the absence of any mechanical contact, so the fundamental effects of friction on surface chemistry requires additional research.

Studies with organic vapors were for the purposes of testing vapors as lubricants or as contaminants. Increased complexity in the form of additional possible chemical reactions adds a layer of intricacy that is absent when studying other gases and vapors. This is especially true for organic contaminants and thermally or electrically activated metals. Noble metal contacts used for electrical switching applications were found to produce a carbonaceous product both when the organic vapor contaminant was controlled [48] and when it was supplied uncontrolled from the ambient [49]. Cyclohexene and 1-hexene were shown to adsorb onto gold surfaces and undergo hydrogenation under friction on the otherwise inert gold surface [50]. No class of organic vapor has seen extensive research in tribology studies between metals. A suite of vapors including alkanes, ethylene, and acetylene were tested on tungsten surfaces using a pin-on-disk apparatus and each vapor was found to significantly decrease adhesion and friction compared to the dry surface [51]. Organic chloride vapors were shown to lubricate in cutting tool experiments although not to the same extent as liquids [52-54]. Phosphate esters at temperatures near $370{ }^{\circ} \mathrm{C}$ and mineral oil at low temperatures offered good lubrication when tested with a four-ball tribo-test apparatus [55,56]. Fundamental studies of adsorbing alcohols on $\mathrm{Cu}(111)$ found that no lubrication was observed below one monolayer of adsorbate and that subsequent adsorbed monolayers decreased friction $[57,58]$. Figure 3 shows the static friction coefficient between self-mated $\mathrm{Cu}$ as a function of trifluoroethanol surface coverage. Unlubricated

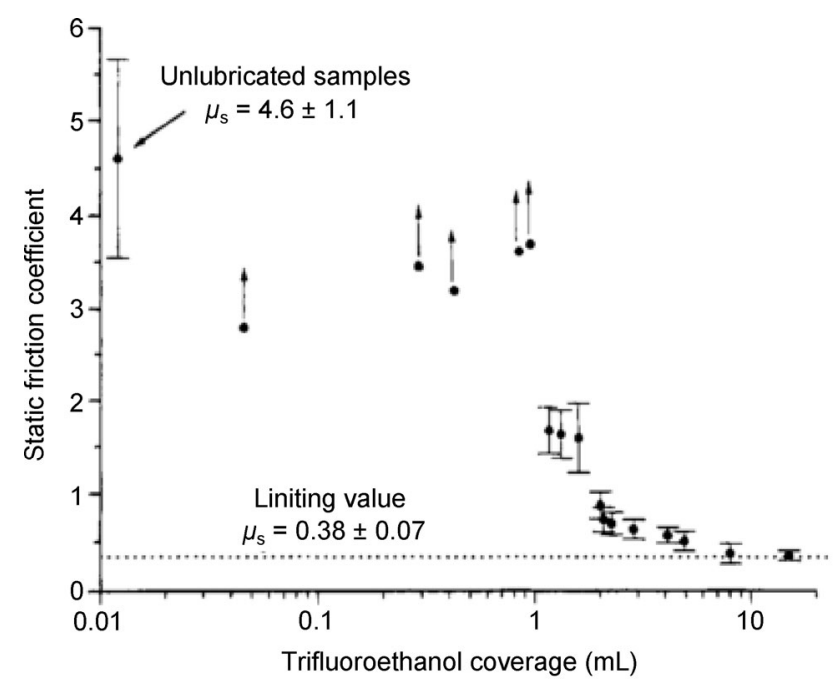

Fig. 3 Relationship between static friction coefficient and trifluoroethanol surface coverage for $\mathrm{Cu}-\mathrm{Cu}$ at $120 \mathrm{~K}$ (performed with a UHV tribometer at $40 \mathrm{mN}$ ). Reproduced with permission from Ref. [58]. Copyrights American Chemical Society, 1995. 
and sub-monolayer coverage give friction coefficients well above 2 while monolayer coverage produces static friction coefficients below 2 and approaching $\sim 0.4$ as coverage increases beyond 10 monolayers [58]. Trimethylborate vapor was also shown to lubricate self-mated steel contact by eliminating the abrasive ware of the iron oxide wear debris [59]. This occurred due to the decomposition of the trimethylborate during the friction tests to methyl and boroxide groups. It was suggested that the boroxide groups reacted with the native iron oxide layer and formed a borate rich transfer film that prevented wear and reduced friction.

\subsection{Environmental effect on friction and wear of ceramics}

Ceramics are commonly used in tribological applications due to their high hardness, low density, and good mechanical stability at high temperatures. A ceramic typically consists of a metal or metalloid bonded to a non-metal. The most common metals or metalloids used in engineering purposes include aluminum, silicon, and titanium while common non-metals include oxygen, nitrogen, and carbon. The adsorption and wear behaviors of oxide ceramics share many properties with glasses and therefore are discussed in Section 2.3. Tribochemistry plays an instrumental role in the friction and wear of ceramics, and have been thoroughly discussed by Fischer [60-62].

Silicon nitride, $\mathrm{Si}_{3} \mathrm{~N}_{4}$, has been the subject of intense tribological research as a wear-resistant high temperature material and a general consensus has been reached on the self-mated sliding friction and wear characteristics of $\mathrm{Si}_{3} \mathrm{~N}_{4}$ in a humid environment [63]. The behavior of friction and wear is largely governed by the extent of tribochemical reactions between the $\mathrm{Si}_{3} \mathrm{~N}_{4}$ surface and adsorbed water, but the adsorbed water affects mechanical properties as well. $\mathrm{Si}_{3} \mathrm{~N}_{4}$ has been found to undergo greater plastic deformation when exposed to humidity [64] possibly due to modification of the dislocation mobility and plastic flow [65]. Increased plasticity was reported for other ceramics as well [66]. The increased plasticity of these materials imparts greater fracture resistance and thus leads to decreased material wear [67].

Tribochemical surface reactions are widely reported for $\mathrm{Si}_{3} \mathrm{~N}_{4}$ in humid environments. The formation of
$\mathrm{SiO}_{2}$ in sliding areas of $\mathrm{Si}_{3} \mathrm{~N}_{4}$ is often observed at all $\mathrm{RH}$, but more readily at higher $\mathrm{RH}$, in both self-mated tests and tests against other materials [60-62, 67-70]. The formed film consisted of an amorphous silicon oxide layer that did not adhere well to the underlying $\mathrm{Si}_{3} \mathrm{~N}_{4}$ [60]. The native oxide layer is spontaneously formed when water vapor is delivered by an inert gas as well as when gaseous oxygen is present. $\mathrm{Si}_{3} \mathrm{~N}_{4}$ rubbed in a pure oxygen environment exhibited a similar tribo-film as that rubbed in a $40 \%-50 \% \mathrm{RH}$ environment [60]. The size of particles composing the tribo-film were found to vary depending on humidity, with smaller particles observed at higher $\mathrm{RH}$ [71]. Investigations into the reaction between water and $\mathrm{Si}_{3} \mathrm{~N}_{4}$ found that $\mathrm{SiO}_{2}$ and ammonia were formed in liquid water [72], although the small amount of ammonia formed from water vapor was not detected. The wear of $\mathrm{Si}_{3} \mathrm{~N}_{4}$ in a dry unlubricated environment consisted mainly of fractured asperities, a mechanism that diminished as RH increased.

In addition to the modification of mechanical properties discussed above, the film formed in $\mathrm{RH}$ can help mitigate $\mathrm{Si}_{3} \mathrm{~N}_{4}$ fracture. Both surface fracture and tribo-film formation occur at low and intermediate RH [60], but wear steadily decreases as RH increases. Wear at high RH consists almost exclusively of hydrated silica and is sometimes referred to as corrosion [69]. The oxides and hydroxides formed at the $\mathrm{Si}_{3} \mathrm{~N}_{4}$ surface in the humid environment are softer than the underlying material, shifting the shear plane from the substrate surface to the film interface. The tribo-film is worn away with each sliding pass but it is also regenerated by the surrounding environment [70]. Although humidity is known to increase crack propagation in many oxide ceramics, the presence of the tribo-film on $\mathrm{Si}_{3} \mathrm{~N}_{4}$ may hinder crack growth and subsequently material wear [67].

Slight differences in wear were observed when $\mathrm{Si}_{3} \mathrm{~N}_{4}$ was mated with other materials. These studies generally used a hard counter-surface (such as diamond [67] or stainless steel [69]) and noticed an increase of $\mathrm{Si}_{3} \mathrm{~N}_{4}$ wear with increasing humidity. Although the mechanisms stated above still work, the deteriorated mechanical properties of $\mathrm{Si}_{3} \mathrm{~N}_{4}$ allows for greater material wear. Additionally, wear particles from the counter-surface can cause third body wear due to plowing [69]. 
While most authors reported similar results regarding wear of $\mathrm{Si}_{3} \mathrm{~N}_{4}$ in humid conditions, the behaviors of the friction coefficient showed large variations. Some studies found that friction coefficient remained constant at or above 0.5 for a range of humid conditions [60, 69], while others reported lower friction coefficients that decreased with increasing RH [68]. Figure 4 shows few ceramics that exhibit decreasing friction as a function of humidity. It was also found that surface roughness and sliding speed can substantially impact friction coefficient in humid environments [60, 69, 73].

Compared to $\mathrm{Si}_{3} \mathrm{~N}_{4}$, other non-oxide ceramics have garnered relatively little study of the effect of the vapor environment on friction and wear. Silicon carbide (SiC) has been shown to form tribo-films similar to $\mathrm{Si}_{3} \mathrm{~N}_{4}$ and follows the same trends of decreasing friction and wear with increasing humidity [68]. On $\mathrm{SiC}$, graphite can be formed by tribochemical reaction and is found in the debris and tribo-film [74]. Gaseous products instead of graphite have also been observed during $\mathrm{SiC}$ wear [75]. Boron carbide films also react with oxygen and water to first form boric oxide and then boric acid [76-78]. Boric acid films then impart low friction and wear. An example of this friction decrease is shown in Fig. 5. The lubricating properties of the boric acid film occurred almost immediately once sliding commenced at high $\mathrm{RH}$ and the steady-state friction coefficient reached a value below 0.1 [78]. Note that the ultra-low friction of boric acid requires the adsorption of water onto boric acid; without water adsorption, boric acid film does not provide lubrication effects [79].

Titanium nitride surfaces have also been shown to oxidize under a humid environment. Friction was found to decrease as humidity increased for TiN sliding against corundum and this corresponded to a change in the wear debris from an amorphous $\mathrm{TiO}_{2}$ at low humidity to a nanocrystalline rutile at high humidity [80,81]. The effect of debris on friction coefficient was explained to arise from the greater fraction of atoms residing in grain boundaries which could impart greater ductility.

Although less common, several studies have investigated the effect of organic vapors on $\mathrm{Si}_{3} \mathrm{~N}_{4}$ and other ceramics for purposes of vapor phase lubrication. High temperature lubrication of $\mathrm{Si}_{3} \mathrm{~N}_{4}$ has been studied with both acetylene [82] and oleic acid with tricresyl phosphate (TCP) [83]. Acetylene was shown to create a

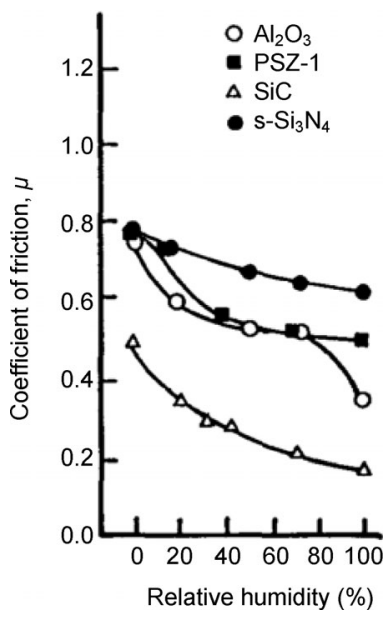

Fig. 4 Coefficient of friction for different ceramic materials at various $\mathrm{RH}$ levels for a pin-on-disk tribometer operating at $4 \mathrm{~cm} / \mathrm{s}$ and $10 \mathrm{~N}$ normal load. Reproduced with permission from Ref. [68]. Copyright Elsevier, 1989.

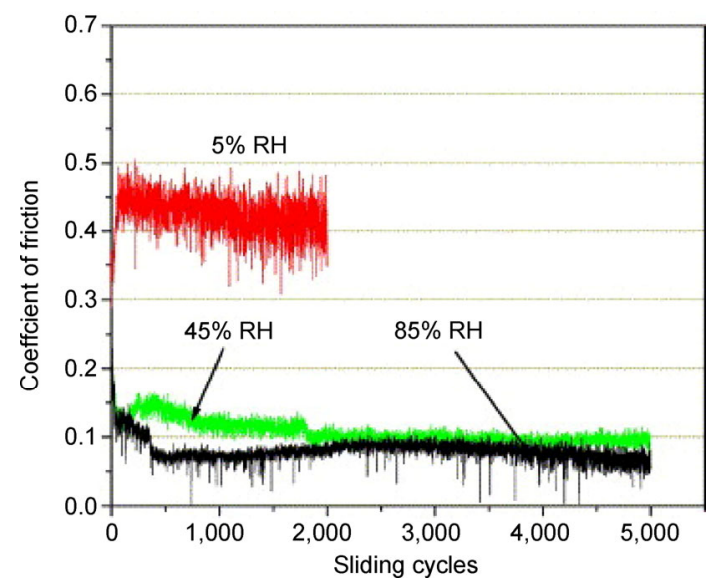

Fig. 5 Coefficient of friction for boron carbide flat against steel ball at various $\mathrm{RH}$ for a pin-on-disk tribometer operating at $4.43 \mathrm{~mm} / \mathrm{s}$ and $0.3 \mathrm{~N}$ normal load. Reproduced with permission from Ref. [78]. Copyright Elsevier, 2006.

tribo-film that was graphitic in nature and decreased the friction coefficient for $\mathrm{Si}_{3} \mathrm{~N}_{4}$ sliding on nickel aluminum alloy by more than an order of magnitude. Tests conducted with oleic acid and TCP found significant friction and wear reductions as well as tribochemical reaction products at the contact points between $\mathrm{Si}_{3} \mathrm{~N}_{4}$ and tool steel, although a detailed description of these reactions was not provided.

\subsection{Environmental effect on friction and wear of oxides and glasses}

The effect of water on the mechanical properties of glass has been an important research topic for many 
decades. Hydration of glass surface by moisture has been widely studied due to its detrimental effects on its properties, such as fracture and fatigue resistance, electrical conductivity, and breakdown of the glass [84-89].

Amorphous silica has been the most extensively examined glass because its tetrahedrally coordinated $\mathrm{Si}-\mathrm{O}$ structure is the basis for the majority of commercial glasses. A Si atom coordinated with three oxygen atoms at the surface is readily hydroxylated by atmospheric water. Siloxane bridges can also chemically react with water to form silanol groups. The silica surface can have three different silanol configurations [90-92]. Free silanols are isolated hydroxyl groups attached to a terminal $\mathrm{Si}$ atom, vicinal silanols involve two individual silanol groups that share a hydrogen bond, and geminal silanols are two hydroxyl groups that are connected to a single $\mathrm{Si}$ atom which is coordinated with two $\mathrm{O}$ in the bulk. A fully hydroxylated silica surface contains about $4.6 \mathrm{OH}$ groups $/ \mathrm{nm}^{2}$ [92].

The adsorption of water on amorphous silica has largely been studied using IR techniques [86, 91, 93-95]. The isolated silanol groups of a silica surface can be identified by a sharp peak at $3,747 \mathrm{~cm}^{-1}$, and physically adsorbed molecular water can be identified by a broad peak centered around $3,400 \mathrm{~cm}^{-1}$. The physically adsorbed water can be removed from the silica glass surface in a vacuum or at the relatively mild heating $\left(120-180^{\circ} \mathrm{C}\right)$ depending on the porosity of the sample. Dehydroxylation of the surface is much more difficult and requires heating at least to the glass transition temperature (typically $>500{ }^{\circ} \mathrm{C}$ ) to completely remove chemically adsorbed silanol groups [90, 92, 95-97].

The multicomponent glass structure differs significantly from crystalline oxide materials, such as silicon oxide and aluminum oxide, which are largely composed of long range ordered crystalline unit cells. The bulk structure of glasses is governed through minimization of internal energy through short range tetrahedral coordination of small, multivalent network cations such as $\mathrm{B}^{3+}, \mathrm{Si}^{4+}$ and $\mathrm{Al}^{3+}$ with oxygen [98]. The metal ions in silicate glasses create highly reactive sites, such as unsaturated network cations, strained siloxane bridges, and non-bridging oxygen (NBO) atoms. Multicomponent glasses often contain alkali metals which do not coordinate with oxygen to continue the glass network but instead form terminal charges. The alkali ions in the glass can leach out upon contact with water [99].

The presence of leachable alkali cations in multicomponent glasses complicates the surface properties of glasses [100-104]. Glasses without alkali metals, such as fused silica, have a minimal hydration layer at the surface, while high alkali glasses can have hydration of the bulk [99]. Alkali ions are leached from the subsurface region and are replaced with ions from the water [99]. In the case of soda lime glass which is the most commonly used commercial glass, the sodium ion leached from glass can be replaced with proton or hydronium $\left(\mathrm{H}_{3} \mathrm{O}^{+}\right)$ions [105-107]. However, these measurements could be affected by the desorption of water in vacuum experimental conditions [108].

The water layer structure adsorbed at the glass surface varies with the glass composition. Figure 6 compares the vibrational sum-frequency-generation (SFG) spectra of water layers on pure amorphous silica (fused quartz) and soda lime glasses in equilibrium with the gas phase. The water layer adsorbed on fused quartz (Fig. 6(a)) behaved like a typical physisorption layer $[93,109]$. The adsorption of water on soda lime glass differed drastically with three distinct peaks identified at $\sim 3,200, \sim 3,430$, and $\sim 3,680 \mathrm{~cm}^{-1}$ (Fig. $6(\mathrm{~b}$ )). The $\sim 3,680 \mathrm{~cm}^{-1}$ peak was assigned to a surface silanol group, while the sharp peak at $\sim 3,200 \mathrm{~cm}^{-1}$ were attributed to water molecules involved in stronglyhydrogen-bonded species near the surface. The $3,200 \mathrm{~cm}^{-1}$ peak intensity grows with increasing the humidity in the ambient gas phase, indicating its equilibrium nature, i.e., its abundance varies with the water activity in the gas phase. The $3,200 \mathrm{~cm}^{-1}$ peak is strongly hydrogen-bonded $\mathrm{OH}$ group; the origin of this sharp feature at $3,200 \mathrm{~cm}^{-1}$ is not well understood yet, but it was tentatively assigned to the hydronium ion (or $\mathrm{H}^{+}$attached to $\mathrm{NBO}$ with additional water molecule) in the $\mathrm{Na}^{+}$-leached site. It was reported that the growth of this peak appeared to correlate with the increase in wear resistance of the soda lime glass surface at high humidities [110]. However, this correlation remains to be tested; it could be simply coincidental. 

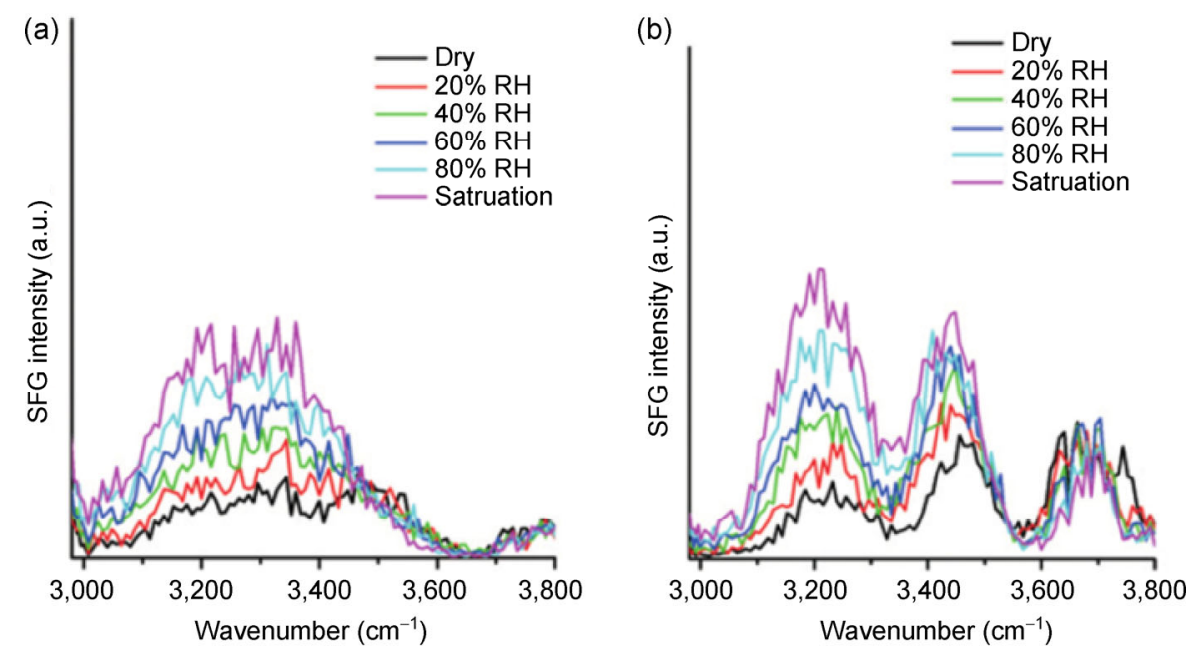

Fig. 6 SFG spectrum of (a) fused quartz and (b) soda lime glass in humid environments. Reproduced with permission from Ref. [110]. Copyright John Wiley and Sons, 2013.

In both silica and multicomponent glasses, a small amount of water adsorbed to the surface increases crack propagation. The stress-corrosion theory of glasses, developed by Charles and Hillig, states that as a tensile stress is applied to a surface defect or a crack, water can react with and dissociate the $\mathrm{Si}-\mathrm{O}-\mathrm{Si}$ bond facilitating the crack propagation [111]. Increasing alkali content increased this stress corrosion effect [84, $98,104,112,113]$. Molecular orbital (MO) calculations suggest that the distorted $\mathrm{Si}-\mathrm{O}-\mathrm{Si}$ bonds with deformed bond angles are the most reactive sites in the $\mathrm{Si}-\mathrm{O}$ network. Molecular dynamics (MD) simulation indicates that the cracks in the fused quartz do not propagate in a dry environment, even if the quartz is under very high strain (up to 23\%) [114]. The MD simulation results also show that the crack propagation at the crack tip is primarily attributed to the hydrolysis of $\mathrm{Si}-\mathrm{O}-\mathrm{Si}$ bonds. As the applied strain increases in humid conditions, both the stress-corrosion and purely stress-induced cracking occurs. The cleavage of siloxane bridges by stress corrosion is relevant to chemical reaction that takes place during the wear of glasses in humid conditions.

Humidity also affects the mechanical failure of glasses under large loads. Scratches made with a Vickers indenter show three regimes based on the loading [115-117]. Under a small load, the scratch develops subsurface lateral cracks; this is called a "micro-ductile" regime. As the load increases, radial and lateral cracks form in a "micro-crack" regime. Finally, in a "micro- abrasive" regime, the scratch path is characterized by large amounts of wear debris. The development of these cracks is facilitated by increasing humidity due to increased crack propagation as expected from the stress-corrosion theory [115-117].

The load and counter-surface chemistry are important factors determining wear behaviors of the glass surface. In atomic force microscopy (AFM) experiments, the amorphous $\mathrm{SiO}_{2}$ was shown to be worn with a $\mathrm{SiO}_{2}$ tip under a low load, while a diamond tip, which is chemically inert yet harder than the $\mathrm{SiO}_{2}$, was unable to wear the Si wafer coated with native oxide under a similar load $[118,119]$. These results suggested that the chemistry of the $\mathrm{SiO}_{2}$ surfaces contributes to the wear of the material at loads lower than the hardness value causing mechanical deformation of the material. The proposed mechanism for wear of the native oxide layer, the creation of siloxane bridges (chemical bonds) [120], could pertain to the glass wear behavior $[121,122]$. A surface force apparatus study found that the adhesion force of two silica surfaces in humid conditions was greater than the capillary force expected from water [123]. The same effect was not seen in hydrophobic surfaces. These results suggested that the hydroxyl groups of the silica react to form chemical bonds across the interface (bridges) through a dehydration reaction [123]. Upon shearing the silica surfaces at adhesive loads, the humid case showed an increase in damage due to the fracturing of the siloxane bridges during sliding. Surface damage was 
not observed between hydrophobic surfaces, suggesting that chemical reaction with water dominates the wear behavior of glass at low loads [123]. Similarly, wear is seen in soda lime glass at low contact pressures, suggesting water-induced chemical reactions between the surfaces [110].

The humidity dependence of soda lime glass wear appears to be quite unique and different from that of other glasses. Figure 7 shows the cross-section of the wear tracks created in difference glasses at the same contact load conditions at $20 \%, 40 \%$, and $90 \% \mathrm{RH}$ conditions. In the case fused quartz, borosilicate (BF33 and AF45), and amulinosilicate glasses, the glass substrate wear increased as RH was raised. In contrast, soda-lime glass shows very little wear in the near saturation humidity condition. Based on the stress corrosion theory $[84,98,104,112,113]$, more wear of glass is expected at higher humidity conditions. This could explain the humidity dependence of wear of fused quartz, borosilicate, and aluminosilicate glasses
(Figs. 7(b)-7(f)). The wear resistance of soda lime glass at near-saturation humidity is not well understood at this moment. It was speculated that the structures of water at the surface and in the subsurface region, which are determined or affected by the presence of leachable $\mathrm{Na}^{+}$ions and types of silicate network, play critical roles in the observed behavior. Somehow, this appeared to counter-act the stress corrosion effect [110].

Wear behaviors of silica glass and soda lime glass are also affected by alcohol adsorption at the surface. Unlike water vapor, adsorbed alcohol vapor was found to reduce wear [124, 126-128]. Density functional theory calculations showed that the difference between water and pentanol vapor effects on silica glass wear might be related to how easily the $\mathrm{Si}-\mathrm{O}-\mathrm{Si}$ bond is cleaved upon impingement of these molecules from the gas phase [128]. The alkoxide termination of $\mathrm{SiO}_{2}$ surface increased the energy barrier required to cleave the $\mathrm{Si}-\mathrm{O}-\mathrm{Si}$ bond compared to hydroxyl termination [128]. Further, it was found that the activation energy
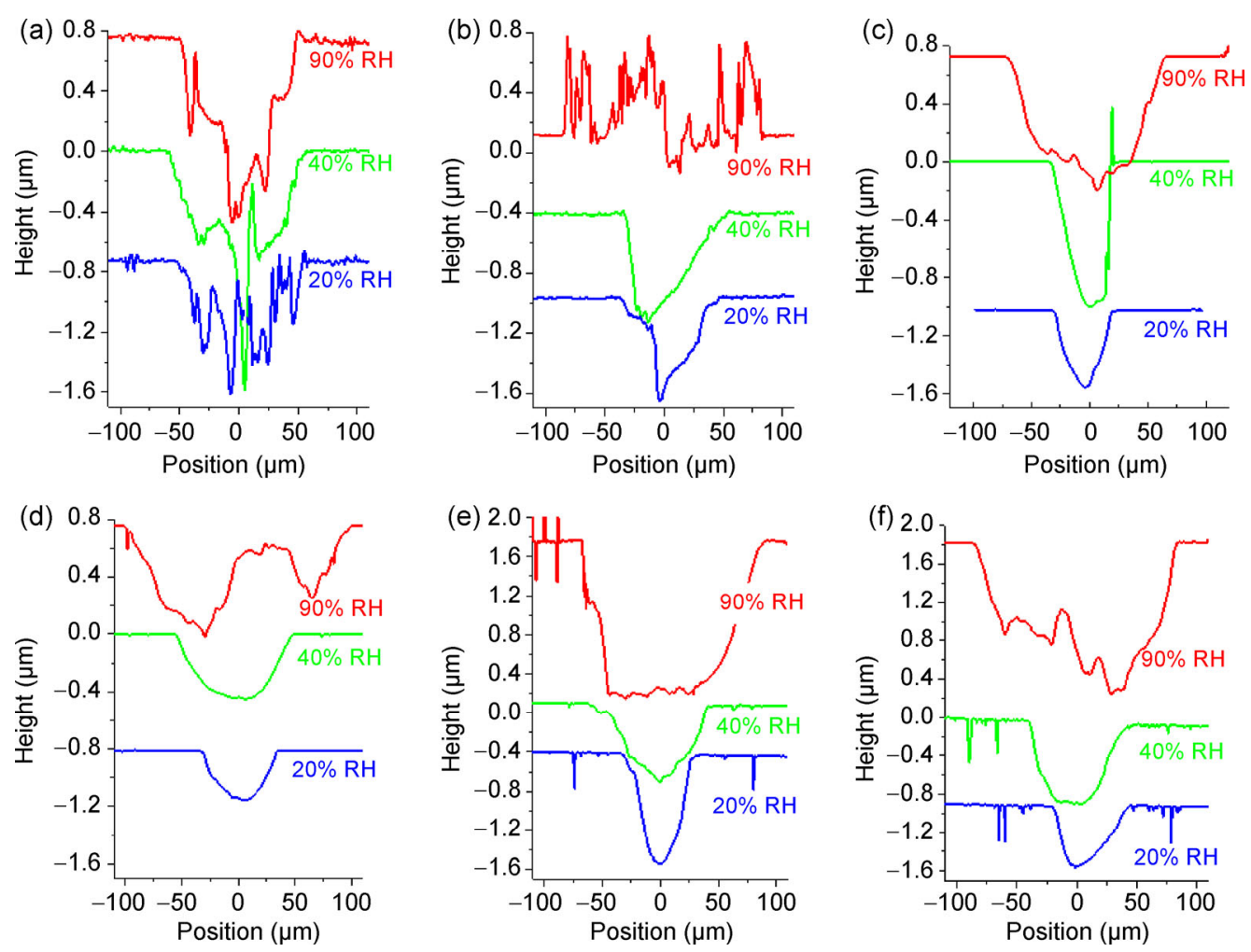

Fig. 7 Line profiles of the wear tracks on different glasses under different humidity conditions: (a) soda-lime silicate glass; (b) fused quartz; (c) BF33; (d) AF45; (e) sodium alumino-silicate; (f) K-exchanged alumino-silicate. (a) and (b) are reproduced with permission from Ref. [110]. Copyright John Wiley and Sons, 2013. (c) and (d) are reproduced with permission from Ref. [124]. Copyright John Wiley and Sons, 2014. (e) and (f) are reproduced with permission from Ref. [125]. Copyright Springer, 2014. 
required to break the $\mathrm{Si}-\mathrm{O}-\mathrm{Si}$ bond is related to the chain length of the terminal alcohol molecules.

Crystalline oxide ceramics, such as $\mathrm{Al}_{2} \mathrm{O}_{3}$ and $\mathrm{ZrO}_{2}$, share many aspects of the chemical properties of amorphous glasses when exposed to environmental water. Crystalline ceramic oxides are susceptible to stress corrosion cracking [129-131]. Similar to glass, at high loads, crystalline ceramics show plastic deformation leading to micro-cracks especially around grain boundaries which are susceptible to slip or delamination [132, 133]. Although water plays a crucial role in increasing surface damage through stress corrosion, water-induced tribochemical reactions can reduce friction and wear [134]. In $\mathrm{Al}_{2} \mathrm{O}_{3}$, an aluminum hydroxide layer can reduce both friction and surface damage. Similar hydroxide lubricating layers can form in zirconia ceramics $[135,136]$. The possibility of several competing mechanisms in humid environments makes wear behaviors of oxides hard to predict; multiple sources reported an increase in wear especially in $\mathrm{ZrO}_{2}[68,129,137,138]$, while other contradicting papers showed a decrease in wear $[129,135,136,139$, 140]. Due to the high variability in the literature, additional studies are still required to further understand the mechanism in oxide ceramics.

\subsection{Environmental effect on friction and wear of carbon materials}

Graphite is a well-known solid lubricant. It has been long believed that graphite lubrication is an intrinsic property of its crystal structure. This conception originated from the interpretation of the graphite structure in which the carbon atoms in basal plane form hexagonal covalent network with $0.142 \mathrm{~nm}$ separation and an inter-planar separation of $0.335 \mathrm{~nm}$ [141]. The wide separation between the planes was thought to be associated with weak van der Waals interaction which allowed the two-dimensional planes to freely slip on top of each other. In the late 1940s Savage disproved this belief [142]. He found that graphite failed to lubricate in vacuum and it wore out into fine dusts due to the strong cohesion between its planes. However, this wear, accompanied by high friction, immediately disappeared in the presence gas molecules such as water vapor, oxygen, alcohol, or alkanes in the surrounding environment [142-145].
The minimum vapor partial pressure required for effective lubrication was experimentally found to decrease logarithmically with the chain length of the vapor in the region 0.5 to $1.5 \mathrm{~nm}$. From these observations, Savage implicitly proposed that the presence of vapor molecules increased the inter-layer separation of graphite and allowed easy slip of graphite planes [144].

A similar lubrication mechanism of graphite in the presence of vapor was proposed based on the reduction of the adhesion forces between graphite layers by adsorbed molecules. Bryant et al. measured the binding energy between graphite layers by cleaving single crystalline graphite in controlled environments [146]. The binding energies between graphite layers in the presence of air, oxygen, or water vapor were significantly lower than their binding energy measured in vacuum. This observation led to a hypothesis that the presence of vapors weakened the interactions between the top surface layer and the bulk of graphite by relaxing the inter-layer $\pi$-electron interaction, which permitted an easy shear of graphite layers.

These models, however, were proven to be incorrect. Surface $x$-ray diffraction of graphite in vacuum, air, and water vapor showed that the inter-layer spacing of graphite basal planes does not change in the presence of oxygen or water molecules [147]. This observation supported the model proposed by Deacon and Goodman that the basal plans of graphite has intrinsic low energy, but they do not slip easily due to high adhesion at the edges of the basal plane; adsorbed molecules are required to reduce the energy of the edge sites to give low friction [148]. Moreover, experiments showed that the presence of water vapor in the environment reduced friction on carbon materials with $\mathrm{sp}^{2}$ valance configuration regardless of their structure [149]. Graphite, non-graphitic carbon, and carbon composites with $\mathrm{sp}^{2}$-only hybridized carbon atoms all gave low friction and wear in humid environment, implying the low friction behavior independent of graphitic layered lattice order. When milled in a planetary mill containing oxygen, scanning electron microscopy (SEM) images showed that, graphite debris was in the form of crystals with sizes in the order of $10 \mu \mathrm{m}$. This is an order of magnitude larger than the debris formed when graphite was milled in nitrogen 
environment [150]. This observation also supported that the oxidation at the edges of graphene planes made the basal planes slip easily, which suppressed basal plane fracturing during the milling process.

Not only does the adsorbed molecule reduce adhesion between the edges of basal planes, there could be oxidation-induced structural changes of the top basal plane. High and room-temperature oxygen treatment of graphene monolayers on platinum and iron substrates distorted the structure of graphene and resulted in the formation of $\mathrm{sp}^{3}$ bonds [151]. Structural changes of graphene layers on $\mathrm{Ru}(0001)$ and $\mathrm{Cu}(111)$ were also reported due to oxidation by water vapor and oxygen. It was found that water and oxygen molecules can react at the line defects of graphene which splits and distorts graphene structure $[152,153]$.

Diamond-like carbon (DLC) is a hard amorphous carbon coating material that is widely used to protect surfaces and obtain low interfacial friction. The friction and wear behaviors of DLC coatings also show sensitivity to the surrounding environment. Adsorbed vapors can reduce adhesion between sliding surfaces by passivating dangling bonds at the surface of DLC [154-157]. For example, non-hydrogenated carbon films (such as tetrahedral amorphous carbon (ta-C)) show low friction coefficient only for a few cycles in vacuum and dry environments, after which the friction coefficient rapidly increases to 1 [158]. The low initial friction coefficient on the non-hydrogenated carbon films is believed to be due to the oxygenated species, adsorbed water, and organic contaminants which passivate the outer surface [159]. Once these species are removed during the first few cycles of sliding, the bare carbon film is exposed and adhesion and friction increase accordingly. Introducing hydrogen to the test environment prevented strong interaction between unsaturated interfacial bonds between carbon films and reduced friction [154,160-163]. When hydrogen partial pressure was increased in the test environment, the ultra-low friction was maintained for longer time. Furthermore, increased hydrogen gas pressure reduced wear of carbon films [161, 162]. Atomistic and molecular dynamic simulations provided theoretical evidence regarding the role of hydrogen in reducing adhesion and friction of carbon films [164-166]. The simulation results showed that the high friction originated from the interfacial bond formation across two sliding carbon surfaces. If the dangling bonds at the carbon surface were passivated by adsorption and reaction with hydrogen, or other gaseous species, adhesion and friction decreased.

The humidity effect on highly-hydrogenated DLC (H-DLC) is quite different from those on ta-C [167-176]. Figure 8(a) compares the humidity effects on both of them [176]. Contrary to a-C, the friction of H-DLC increases with increasing RH. H-DLC shows ultra-low friction $(<<0.1)$ in dry conditions, while ta-C shows high friction $(>0.1)$. With increasing water partial
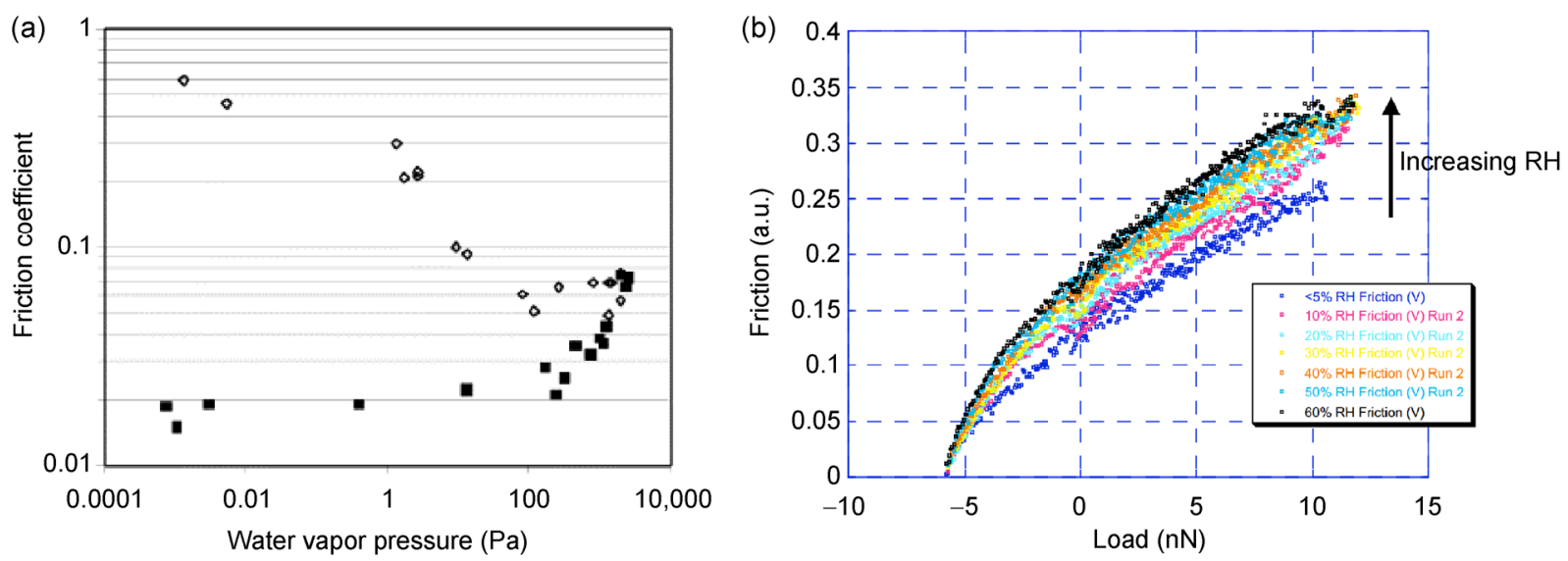

Fig. 8 Effect of humidity on friction and adhesion of DLC. (a) Friction coefficient of self-mated tetrahedral amorphous carbon (open squares) and hydrogenated diamond-like carbon (solid squares) as a function of water vapor partial pressure. Data collected using a pin-on-disk tribometer. (b) Micro-scale friction vs. load curves for silicon nitride AFM tip and a flat diamond-like carbon surface at varying relative humidities. (a) is reproduced with permission from Ref. [176]. Copyright Elsevier, 2003. (b) is reproduced with permission from Ref. [177]. Copyright American Chemical Society, 2004. 
pressure, the friction coefficients of these two surfaces become closer and converge to the same value (around 0.1) when the humidity is high enough for a monolayer of adsorbed water to form on the surface. This result indicates that the hydrogen content and structure are not main determinants for friction in humid ambient; the adsorbed water molecules determine the friction behavior. However, the effect of humidity on amorphous and diamond-like carbon coatings is not fully understood yet. Carpick et al. reported a lack of correlation between friction and adhesion on DLC under varying water vapor partial pressures (Fig. 8(b)) [177]. Using AFM, they observed a monotonic increase in friction with increasing humidity while adhesion stayed constant. This unusual behavior and other behaviors of carbon films in different environments are still an active area for research.

Diamond-like carbon coatings are usually considered inert [170, 178, 179]. Water contact angles on H-DLC reported in literature ranged from $65^{\circ}$ to $100^{\circ}$ [180-182]. The adsorption behavior of water on H-DLC was found to be between type II and type III adsorption isotherms [183]. This implied that the isosteric heat of water adsorption on DLC is only slightly higher than the heat of liquefaction of bulk water, indicating a weak interaction between water and H-DLC compared to water and materials that exhibit type II adsorption. DLC, however, is not completely inert especially under sliding action where wear and bond-breaking continuously occur increasing the surface area by creating wear debris and exposing fresh surfaces with unsaturated bonds [184]. The run-in behavior, which is the period of high friction that precedes the ultralow friction in dry environment, was found to be a result of removal of the oxide layers [185]. Furthermore, the length of the run-in period was found to correlate with the thickness of the H-DLC oxide [186].

Figure 9 shows how brief exposure of DLC to oxidants interrupts the ultra-low friction and results in a run-in behavior [154]. After the initial run-in period in dry Ar, the surface oxide layer is removed and the ultra-low friction state is reached (friction coefficient $<0.01$ ), sliding was interrupted and the H-DLC surface was exposed to humid or alcohol vapor environment
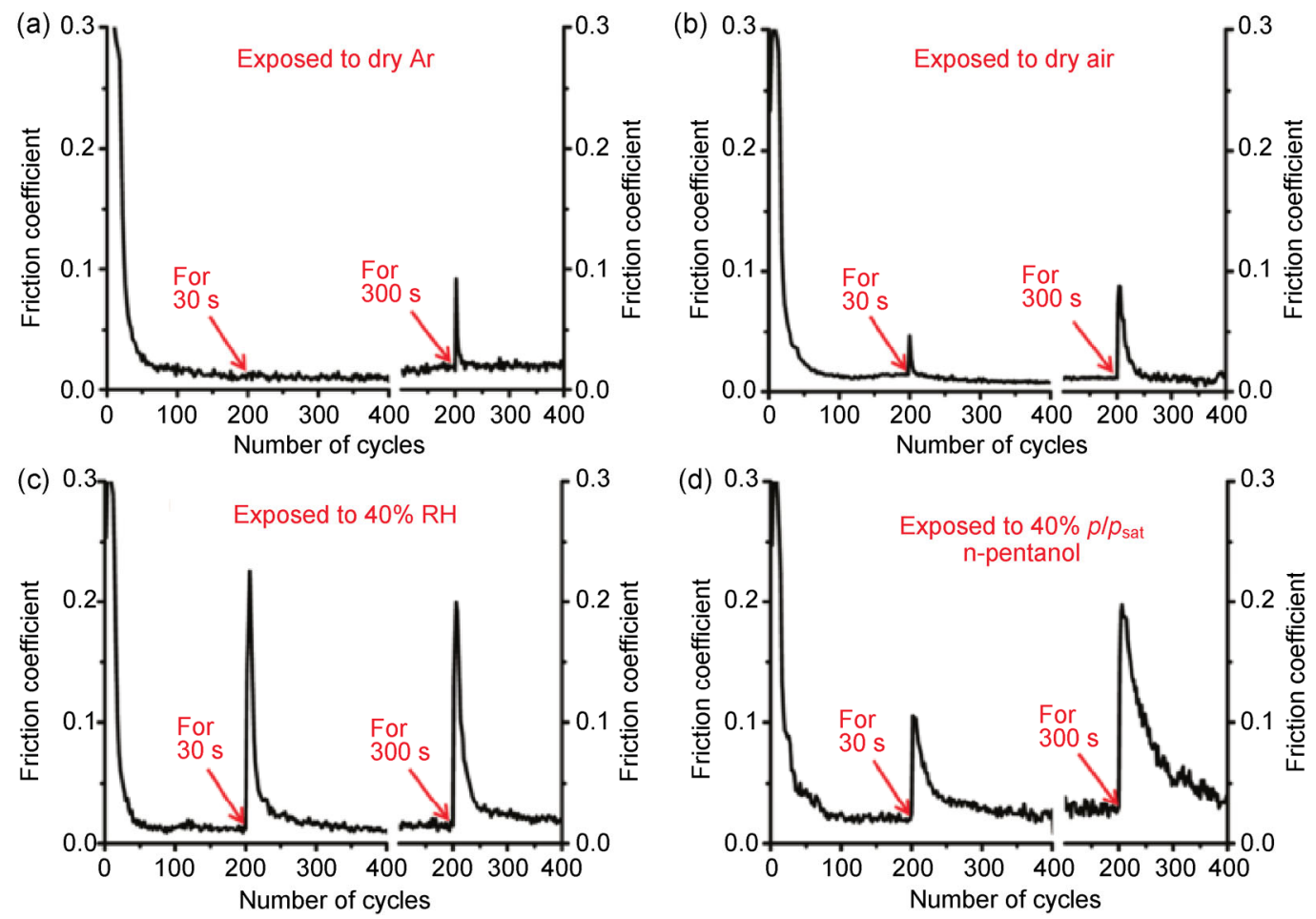

Fig. 9 Friction coefficient of self-mated highly-hydrogenated DLC as a function of reciprocating cycle in dry Ar measured using a ball-on-flat tribometer. The test was stopped and the ball was lift-off the H-DLC surface for exposure to (a) dry Ar, (b) dry air, (c) humid $\mathrm{Ar}$, and (d) pentanol vapor-containing Ar for specific time. Tests were then resumed in dry Ar to reach the ultra-low friction of H-DLC. Reprinted with permission from Ref. [154]. Copyright American Chemical Society, 2011. 
for a specific amount of time, then the friction test was resumed in dry Ar. The friction coefficient did not increase when sliding was paused for $30 \mathrm{~s}$ in dry Ar, but it spiked up to 0.1 and decreased back quickly to the ultra-low friction when the sliding was paused for $300 \mathrm{~s}$ (Fig. 9(a)). The increase in friction after the prolonged pause was due to the oxidation by the traces of oxygen and water vapor (4-5 ppm) in the dry argon used. This shows how reactive DLC is towards even a small concentration of oxidants. H-DLC surface oxidized faster when it was exposed to dry air or humidity (Figs. 9(b) and 9(c)). The freshly formed oxidized H-DLC was removed when sliding was resumed, which reduced the friction coefficient gradually back to the ultra-low value. Similar trend was observed for pentanol vapor too, but the reaction products formed on H-DLC surface in the pentanol vapor seemed to be different from the reaction products that formed when H-DLC was exposed to oxygen or water vapor. Figures 9(d) shows that the rate of removal of the pentanol-induced oxide layer was slower than the rate of removal of oxygen or water-induced oxide layers. The slower removal indicates a different nature of the pentanol-induced oxide which can be responsible for the wear prevention compared to water vapor and oxygen [154].

Although made of the same carbon materials, ultra-nano crystalline diamond (UNCD) and ta-C show drastically different dependence of friction on humidity compared to DLC. Just like H-free a-C, they exhibit a decrease in friction coefficient in the presence of water vapor [176]. The main difference of UNCD and ta-C from H-DLC must come from the difference in the surface energy and reactivity of the surfaces of these materials [187]. On UNCD, Konicek et al. found that, at low normal loads, an RH of as low as $0.5 \%$ was sufficient to eliminate the run-in period of high friction and gave ultra-low friction coefficient $[188,189]$. The ultra-low friction required a higher $\mathrm{RH}$ under higher normal loads during the friction tests. In addition, from ex-situ photoelectron emission microscopy, it was concluded that the UNCD did not graphitize during the friction test. This confirmed that the observed lubricity was a result of the surface passivation by water vapor, not a structural change in the UNCD film.

Another important environment dependent behavior of DLC is the formation of transfer film within the contact area. Transfer film is an indication that wear of carbon film takes place, and can result in coating failure in some cases. Donnet et al. used in-situ Auger electron spectroscopy (AES) to study transfer film formation during friction tests on H-DLC using a steel counter surface in a range of oxygen and water vapor partial pressures [169]. The friction coefficient of the DLC was found to be independent on the oxygen pressure, and so was the amount of the transfer film formed. On the other hand, increasing water partial pressure increased the friction coefficient. The increase in friction was accompanied by thinning of the transfer film. It was concluded that water inhibited the formation of thick transfer film, and thus friction did not decrease to its ultra-low state. Similarly, the presence of pentanol molecules in the vapor during sliding on H-DLC completely suppressed the formation of transfer film and increased the friction to 0.15 [154].

\subsection{Environmental effect on friction and wear of polymeric materials}

Polymers and plastics are exceptional materials in that they can be easily molded and can be synthesized to have superior chemical resistance. Polymers have a unique ability to absorb vapor molecules through the surface and into the bulk [190,191], a characteristic that is not present in most other inorganic materials. Water absorption is especially important in the plasticization of polymers [192] and the biocompatibility as it is the case in contact lenses [193].

Although vapor absorption studies are prevalent for polymeric materials, vapor adsorption onto polymer surfaces has been studied much less. Commonly-used adsorption characterization techniques could not be able to distinguish vapor adsorbing onto the surface from vapor absorbing into the bulk. An investigation into the polymer-water vapor interactions using a combination of attenuated total reflection infrared (ATR-IR) spectroscopy and vibrational SFG spectroscopy was able to distinguish water on the polymer surface versus water within the polymer [194]. In the study, a polydimethylsiloxane (PDMS) containing ionic side groups was coated onto a $\mathrm{SiO}_{2}$ surface to form a $\sim 4 \mathrm{~nm}$ thick film. The SFG signal is selectively generated at interfaces whereas the ATR-IR signal observes 
molecules both in the bulk film and at the film interface. The difference in SFG and ATR-IR spectra shown in Fig. 10 indicated that water absorbs into the polymer film due to hygroscopic nature of the film, but it does not adsorb onto the surface of the polymer due to the hydrophobic nature of the film surface [194]. The hydrophobic nature is due to the methyl groups from the PDMS backbone that are exposed to air, while the hygroscopic nature is due to cationic groups and counter ions present within the film.

Polymers used in tribological applications can have multiple distinct components to impart added mechanical strength or better wear resistance. Fibrous composites have shown to improve tribological performance, but the presence of the fiber can complicate the material response to the surrounding vapor environment $[195,196]$. Sorption of water by these fibers, especially natural fibers, can cause degradation of the mechanical properties of the polymer $[195,196]$. The hydrophilic nature of the natural fibers leads to increased water absorption as well as physical swelling. The presence of water in these fibers can lead to decreased chemical compatibility with the hydrophobic polymer matrix, which can cause decreased adhesion between the fiber and polymer matrix and in turn poorer mechanical properties [197]. The study of the organic fibers also constitutes an important area of research in the polymer field. Cellulose, the most abundant biopolymer, and cellulose-derived fibers are important to the paper and textiles industries. An increase in friction and adhesion as $\mathrm{RH}$ increased from $8 \%$ to $40 \%$ was found for cellulose surfaces at the nano-scale [198]. This increase was explained by

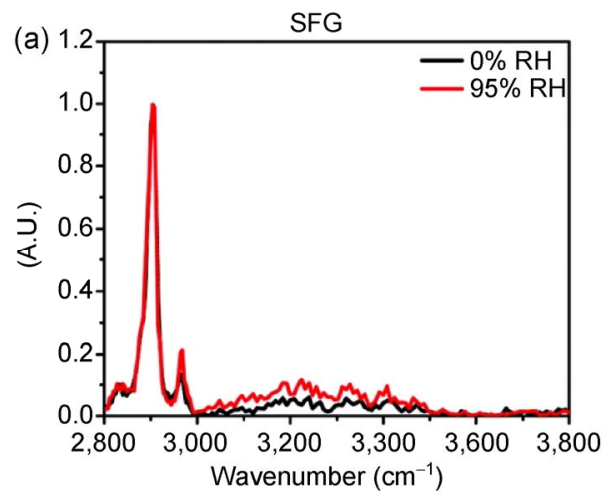

the formation of capillaries at the contact point and the subsequent increase in the Laplace pressure contribution to adhesion force.

The formation and role of the transfer film is perhaps the most important aspect in polymer tribology. This film can form when the polymer rubs against a different material such as a metal, or between two different polymers, by transferring from the polymer of low cohesive energy to the one of higher adhesive energy [199]. The mechanism by which adsorbing vapors modify the transferred film formation is primarily what dictates how the vapor environment affects polymer tribology.

No universal trend of friction behavior in the presence of humidity can describe all polymeric materials although common mechanisms are seen across different materials. Many polymers, especially synthetic polymers such as polytetrafluroethylene (PTFE, also known as Teflon), are hydrophobic. The hydrophobicity has been used to explain why no change was observed in friction against polyimide at higher humidities [200] or with PTFE at lower humidities [201]. However, tests over a wider range of RH have found noticeable friction and wear differences for synthetic polymers. High density polyethylene (HDPE) and PTFE tests taken from a dry state to near saturation experienced a significant increase of wear while sliding against a metal pin [202]. The increase in polymer wear was found to correlate with a less-uniform transfer film onto the metal pin, with large areas of no material transfer observed as opposed to the uniform film at intermediate RH. Poor adhesion of the polymer to the metal at high RH yielded the non-uniform film, and

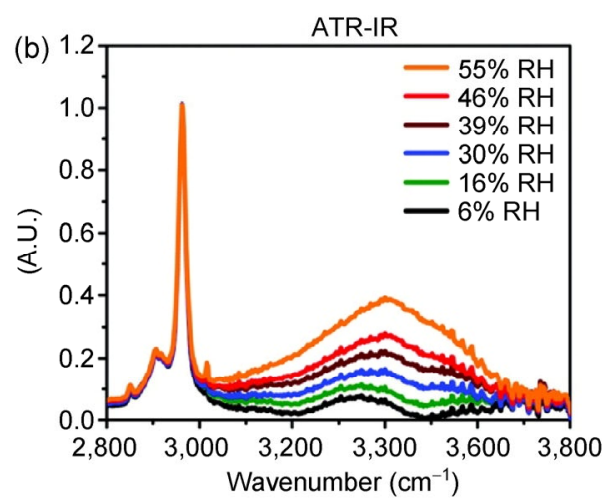

Fig. 10 (a) SFG spectra at the polymer/air interface at dry and 95\% RH and (b) ATR-IR spectra at various RH for polymer deposited on an ATR crystal. Reproduced with permission from with permission from Ref. [194]. Copyright American Chemical Society, 2011. 
this weakness in film adhesion along with sorption of water into the polymers was cited as a cause for the increased wear [202].

The addition of stabilizing or strengthening components can change these behaviors. Tests using rubber composite materials in brake pads found higher tribofilm formation in dry than in a humid environment [203]. However, since the tribo-film consisted of a significant amount of iron from the counter-surface, this tribo-film increased friction in the system. Alumina particles added to PTFE showed a consistently decreasing wear rate as $\mathrm{RH}$ increased from under $1 \%$ to near $90 \%$ RH [204]. Figure 11 shows the relationship between wear and humidity for the control and composite surfaces. The control sample without the alumina particles showed no RH dependence of wear. The addition of alumina greatly lowered wear rate at all vapor conditions, and increasing humidity also produced a decrease in wear rate. Investigations of the tribo-film formed on the composite sample in a dry environment versus in humid environments found significantly different carbonaceous components between two environments. These additional species present in RH conditions suggest that a tribochemical reaction has occurred [204].

Tribology-induced reactions between polymers can lead to tribo-electrification or tribo-luminescence. The effect of humidity on these properties was studied

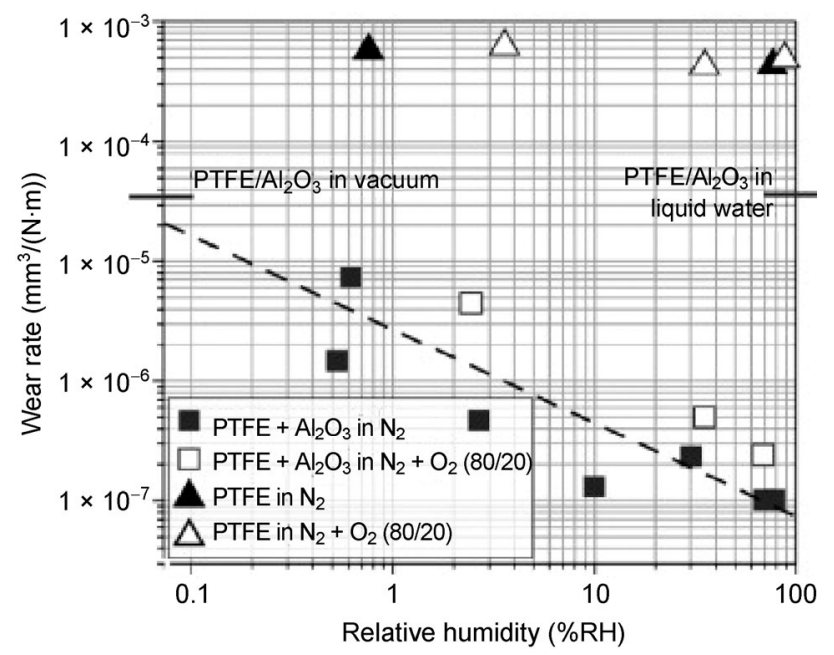

Fig. 11 Wear rate for PTFE/alumina composite and PTFE control in various $\mathrm{RH}$ and oxygen environments conducted using a pinon-disk tribometer operating at $50.8 \mathrm{~mm} / \mathrm{s}$ and $250 \mathrm{~N}$ normal load. Reproduced with permission from Ref. [204]. Copyright Elsevier, 2012. for a large variety of polymers including PTFE, polyethylene (PE), polyvinyl chloride (PVC) and others [205]. Electrical charge on the surface was found to increase as $\mathrm{RH}$ went from dry to $10 \% \mathrm{RH}$ for many of the polymer combinations and reached a charge maximum at an $\mathrm{RH}$ between $10 \%-30 \%$ depending on the specific materials, after which charge decreased. This non-monotonic behavior is explained by the competition between charge generation from friction and charge leakage to the atmosphere. As water vapor is introduced, charge can be conveyed by $\mathrm{H}^{+}$and $\mathrm{H}_{3} \mathrm{O}^{+}$ cations and $\mathrm{OH}^{-}$anions. Further increases in $\mathrm{RH}$ result in the formation of leakage paths and the recombination of the ions [205].

\section{Surface roughness effects on vapor phase lubrication}

The effect of surface roughness on friction depends on the lubrication regime that describes the sliding contact. In the hydrodynamic regime, where the liquid lubricant film is so thick that no immediate contact between the sliding surfaces takes place, surface roughness affects friction by changing the pressure distribution within the contact area [206, 207]. In the boundary and mixed lubrication regimes, where intimate contact between sliding surfaces takes place, surface roughness, both natural and engineered, can affect friction in various ways. It can increase the friction and result in catastrophic wear if the asperities break during sliding. This happens when the local pressure at these asperities is larger than the yield strength of the material, which causes it to fail [208]. Engineered surface texture such as wells, dots, and grooves, in contrast, can reduce friction and wear if designed correctly to act as channels or reservoirs for liquid replenishment [209]. Surface roughness can also directly reduce the intimate contact area by entrapping liquid lubricant in its depressed regions, shifting the lubrication more towards lower shear mixed regime [210].

Lubrication by adsorbed vapor layer(s) falls in the boundary lubrication regime. However, the thickness of the adsorbed vapor molecules on solid surfaces (on the order of angstroms or a nanometer) is much smaller than the roughness of most macro-scale surfaces 
used in engineering applications [211]. Therefore, it was often thought that adsorbed vapors would not be sufficient to lubricate asperities of rough surfaces; but this is an incorrect misconception originated from picturing the vapor phase lubrication similar to the mixed lubrication in liquids. Figure 12 shows the difference in the effect of surface roughness on friction in liquid pentanol and adsorbed monolayer of pentanol vapor on flat and nano-textured DLC. The nanotextured DLC has topographic features ( $100 \mathrm{~nm}$ from peaks to valleys) much larger than the size of pentanol molecules. The friction behavior and schematic describing liquid pentanol lubrication on flat and nano-textured DLC are shown in Fig. 12(a). When a linear liquid molecule is used as a lubricant on flat DLC, the high contact pressure causes deformation of the DLC surface, which is larger than the topographic features size, and expels most of the molecules outside the contact area. The molecules left within the contact area make few layers of long-range ordered films giving high shear and friction due to their increased viscosity and density [210]. However, liquid entrapped inside the depressed regions of the surface texture does not form the long-range ordering and reduces the actual area of high shear; thus, the friction of the nanotextured DLC surface is measured to be lower than that of flat DLC in liquid pentanol lubricant. In contrast, when vapor lubricant is used, the absence of liquid results in a nearly complete deformation of the surface features, and the flat and the nano-textured surfaces give similar friction coefficient (Fig. 12(b)). Note that the molecules adsorbed on the surface do not flow like a bulk fluid. They remain in the contact region as adsorbates mitigating the interfacial shear behavior.

The data obtained with the textured H-DLC demonstrated that as long as the Hertzian deformation of the topographic features does not induce mechanical wear nor further roughens the track, then the adsorbed layer of simple molecules should be able to lubricate the sliding interface [210]. This was proven by testing various simple organic molecules on a number of solid materials with different modulus, hardness, and surface roughness (Fig. 13) [211]. Figure 13(a) shows how different pairs of materials gave varying friction coefficients in dry environment. When pentanol vapor is introduced (Fig. 13(b)) to the sliding interface, the friction coefficients of the different combinations of sliding surfaces of different materials converged to a narrow range $(0.12 \sim 0.2)$. Figure 13 (c) contains information about the pairs of materials used in friction tests in Figs. 13(a) and 13(b). It should be noted that adsorbed pentanol vapor lubricates even on surfaces where the mean roughness is orders of magnitude larger than the adsorbed molecule. The absence of wear debris suggested that plastic deformation occurred rather than breaking of asperities [211]. This also indicates that the presence of the adsorbed molecule (a)
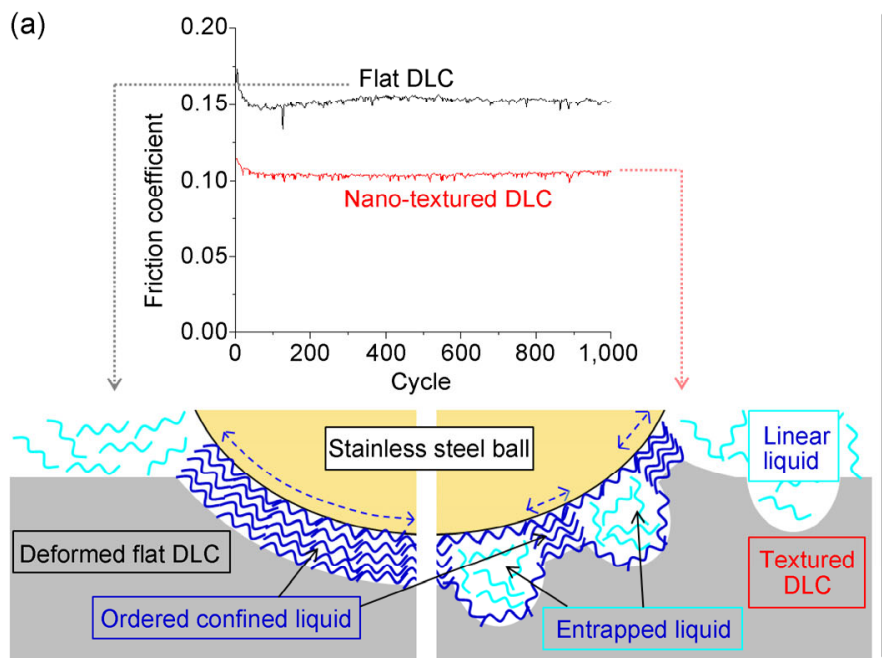

(b)

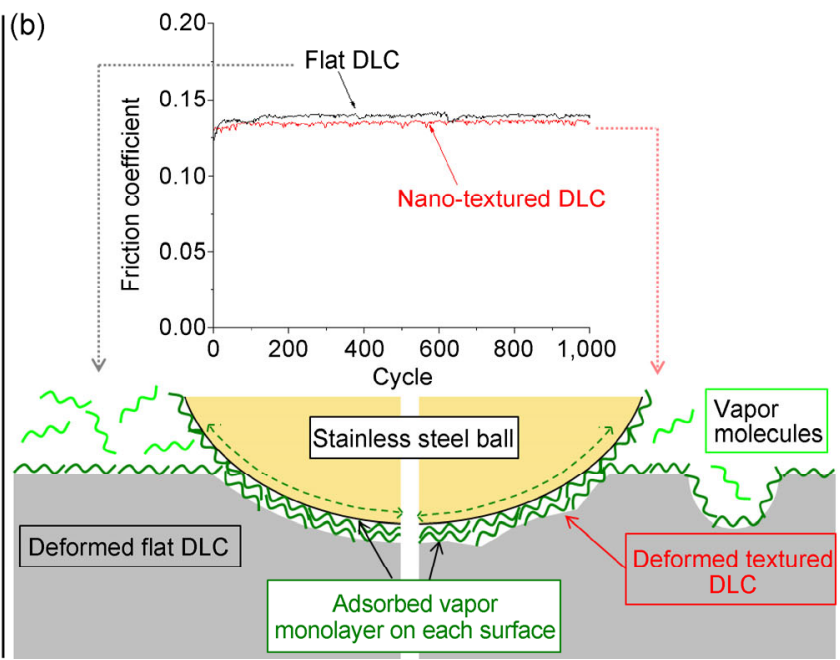

Fig. 12 Friction coefficient on flat and nano-textured DLC in (a) liquid pentanol and (b) adsorbed pentanol vapor. Deformation mainly occurred on the DLC surface due to its lower elastic modulus. Adapted with permission from Ref. [210]. Copyright American Chemical Society, 2013. 

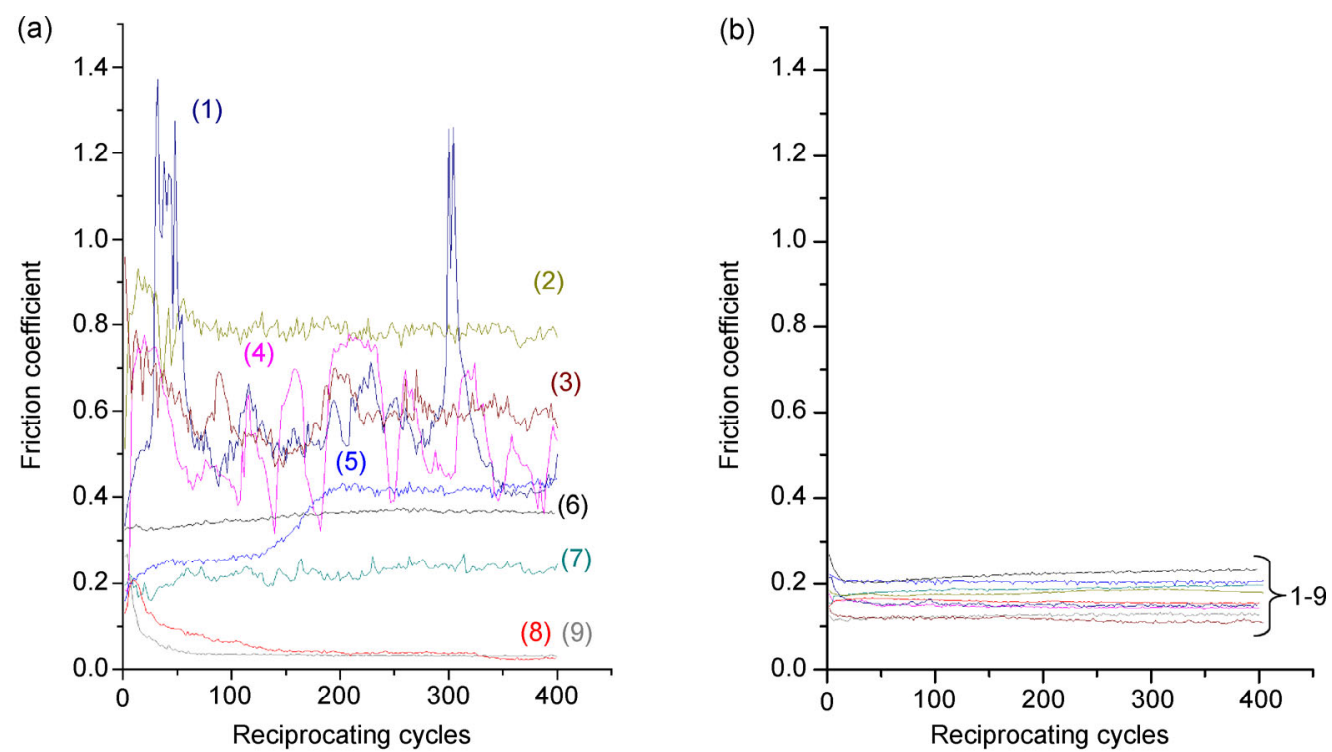

\begin{tabular}{|c|c|c|c|c|c|c|}
\hline & $\begin{array}{c}\text { Elastic } \\
\text { modulus } \\
(\mathrm{GPS})\end{array}$ & $\begin{array}{c}\text { Applied } \\
\text { load }(\mathrm{N}) \& \\
\text { ball material }\end{array}$ & $\begin{array}{c}\text { Hertzian } \\
\text { pressure } \\
(\mathrm{MPa})\end{array}$ & $\begin{array}{c}\text { Hertzian } \\
\text { diameter } \\
(\mu \mathrm{m})\end{array}$ & $\begin{array}{c}\text { Elastic } \\
\text { indentation } \\
\text { depth }(\mathrm{nm})\end{array}$ & $\begin{array}{c}\text { Roughness } \\
(\mathrm{nm}, \mathrm{rms})\end{array}$ \\
\hline $440 \mathrm{C} \mathrm{SS}$ & 200 & $0.1 / \mathrm{SS}$ & 373 & 18.5 & 28.5 & $\sim 25$ \\
\hline Inconel & $\sim 210$ & $0.1 / \mathrm{SS}$ & 380 & 18.3 & 27.9 & $\sim 45$ \\
\hline $\mathrm{Cu}$ & 130 & $0.1 / \mathrm{SS}$ & 325 & 19.7 & 32.3 & $\sim 40$ \\
\hline $\mathrm{Pd}$ & 120 & $0.1 / \mathrm{SS}$ & 323 & 20.3 & 34.3 & $\sim 140$ \\
\hline $\mathrm{Si}_{3} \mathrm{~N}_{4}$ & $\sim 225$ & $0.1 / \mathrm{Si}_{3} \mathrm{~N}_{4}$ & 382 & 18.2 & 27.6 & $<10$ \\
\hline $\mathrm{Si}$ & 160 & $0.1 / \mathrm{SiO}_{2}$ & 340 & 19.3 & 31.0 & $\sim 1$ \\
\hline $\begin{array}{c}\text { Soda-lime } \\
\text { glass }\end{array}$ & 70 & $0.2 / \mathrm{Pyrex}$ & 290 & 29.7 & 73.5 & $<1$ \\
\hline $\mathrm{DLC}$ & $\sim 65^{26}$ & $1.0 / \mathrm{SS}$ & 458 & 52.7 & 231 & $\sim 3$ \\
\hline Polycarbonate & $\sim 2$ & $0.1 /$ Acrylic $^{*}$ & 21.5 & 77.0 & 467 & $\sim 3$ \\
\hline
\end{tabular}

Fig. 13 Friction coefficient results for different material combinations in (a) dry nitrogen, and (b) $40 \% P / P_{\text {sat }}$ n-pentanol. (c) Material combinations tested and their mechanical properties, surface roughness, and contact parameters. Material combinations that are listed as numbers and colors are (1, navy) palladium vs 440C SS ball; (2, olive) $\mathrm{Si}_{3} \mathrm{~N}_{4}$ vs $\mathrm{Si}_{3} \mathrm{~N}_{4}$ ball; (3, maroon) $440 \mathrm{C} \mathrm{SS}$ vs 440C SS ball; (4, magenta) sodalime glass vs Pyrex ball; (5, blue) copper vs 440C SS ball; (6, black) Inconel vs 440C SS ball; (7, cyan) $\mathrm{SiO}_{2}$ vs fused silica ball; (8, red) H-DLC vs 440C SS ball; and (9, gray) H-DLC vs H-DLC-coated ball. Reproduced with permission from Ref. [211]. Copyright American Chemical Society, 2014.

shifted the shear plane from the solid-solid interface to the adsorbate/solid interface, protecting surfaces from wearing.

This study also showed that the friction coefficient of stainless steel pairs in vapor phase lubrication condition vary slightly depending on the molecular structure of the adsorbing molecule [211]. For the normal alcohol series, the friction coefficient decreases as the alkyl chain length increases. The linear chain alcohol appears to be more efficient for vapor phase lubrication than the branched chain alcohol with the same carbon number. The simple hydrogenated alcohol works better than fluorinated alcohol.

\section{Applications of vapor phase lubrication}

\subsection{Vapor phase lubrication of MEMS devices}

High friction and wear of microelectromechanical systems with moving parts is a major obstacle in the way of applying them in many engineering applications [212]. Due to their small sizes, MEMS have high 
surface to volume ratios. This makes the effect of body forces insignificant when compared to surface forces such as capillary and adhesion. Due to strong adhesion and friction forces, MEMS operation initially requires large actuation forces to begin operation, and adhesion will eventually result in wear and failure of MEMS devices [212].

Thin organic films and hard coatings have been shown to lubricate MEMS. However, durability and reliability of such lubrication techniques should be taken into account. Organic layers are susceptible to degradation even under normal storage conditions. Hard coatings are prone to wear under prolonged sliding which limits the device lifetime [212, 213]. Moreover, a conformal coating using organic and inorganic coatings is hard to achieve on surfaces buried in complex microstructures [212].

Vapor phase lubrication of silicon oxide surfaces has been shown to be effective and reliable on the macro to the nano-scales [214, 215]. Pentanol vapor lubrication completely prevented failure of MEMS devices; as Fig. 14 shows, a MEMS device operated in dry conditions failed after less than 10,000 cycles (less than two min at a $100 \mathrm{~Hz}$ operation). In contrast, when the MEMS device was operated in the presence of pentanol vapor, the device ran for 11 days without failing or any sign of wear [215]. Under prolonged operation of the MEMS device at low partial pressure of pentanol vapor, a high molecular weight material was detected within the sliding area [215]. This material is called tribo-polymer and it is an undesired product as it indicates materials wear during sliding [216]. Wear of the silicon oxide can occur due to insufficient supply of the lubricating molecules from the surrounding vapor [216]. Section 4.2 offers a more detailed discussion about the mechanism and the causes for forming undesirable tribo-products.

It has also been shown that pentanol adsorption on MEMS devices does not result in stiction problem due to capillary forces [214]. This is because the increase in adhesion is modest and does not interrupt the operation of the MEMS device. Figure 15 shows that the adhesion force of the micro-fabricated MEMS sidewall surfaces increased from $\sim 30$ to $\sim 60 \mathrm{nN}$ as the pentanol forms the first monolayer around $20 \% P / P_{\text {sat }}$ and only slightly increases to $\sim 75 \mathrm{nN}$ at $95 \% P / P_{\text {sat }}$. This increase is considered small and does not affect MEMS operation since most on-chip actuators are capable of overcoming such adhesion forces.

Adsorbed water vapor, due to capillary forces and the subsequent strong adhesion forces, is detrimental for MEMS operation [217, 218]. Environments of relative humidities as low as $1.8 \%$, were not only found to increase stiction and require very large actuation force to drive the movement of MEMS parts, but they also induced catastrophic wear and ultimately led to device failure [217]. The devastating effects of humidity, however, were found to be significantly mitigated in the presence of organic vapors. As Fig. 16 shows, in environments containing $50 \% P / P_{\text {sat }}$ of pentanol, MEMS

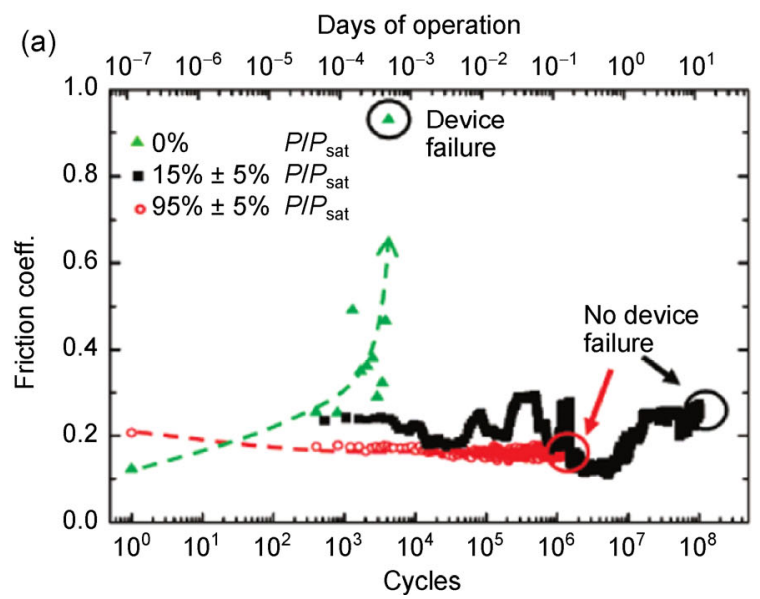

(b)

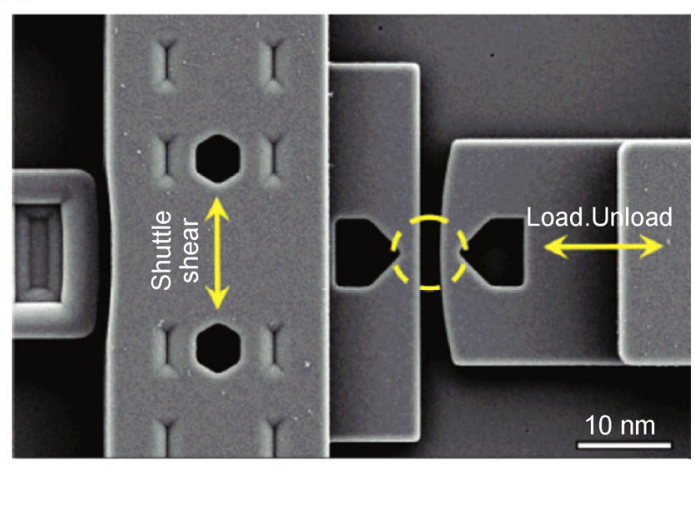

Fig. 14 (a) Friction force vs. cycles in an MEMS sidewall device under $500 \mathrm{nN}$ load at $100 \mathrm{~Hz}$ oscillation in dry nitrogen, $15 \%$, and $95 \% P_{\text {sat }}$ of pentanol vapor. (b) MEMS sidewall friction device. The post moves perpendicular to the contact area (circled) and is used to apply the load while the shuttle moves laterally to the contact. Reproduced with permission from Ref. [215]. Copyright American Chemical Society, 2008. 


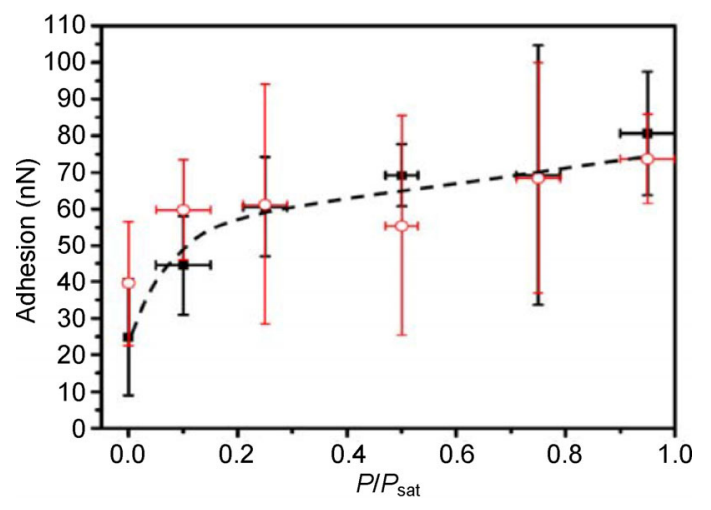

Fig. 15 Adhesion force of two different MEMS sidewall devices as a function of the relative partial pressure of 1-pentanol $\left(P / P_{\text {sat }}\right.$ where $P_{\text {sat }}$ is the saturation pressure of the alcohol). Reproduced with permission from Ref. [214]. Copyright Springer, 2008.

devices operated without showing any significant signs of wear when the humidity was as high as $30 \%$ [219]. Furthermore, increasing RH up to $30 \%$ did not have significant effect on the adhesion force measured in the MEMS device. It was suggested that the insensitivity of the adhesion force to $\mathrm{RH}$ in the presence of pentanol vapor is due to the structure of the co-adsorbed water and pentanol layer. The binary adsorbate layer was found to be terminated with the alcohol groups [220]. If that structure persisted for the different pentanol-water environments, then the surface energy of the adsorbate will remain the same and the adhesion forces will not vary significantly [219].

When the relative humidity increased above 30\%, pentanol vapor could no longer suppress the effect of adsorbed water [219]. This was found to originate from the competition between water and pentanol vapor molecules to adsorb on silicon oxide. Increasing relative humidity increased water adsorption and gradually decreased pentanol vapor adsorption to the point where the amount of adsorbed pentanol is not sufficient to effectively lubricate the contact. These finding are important because they allow for
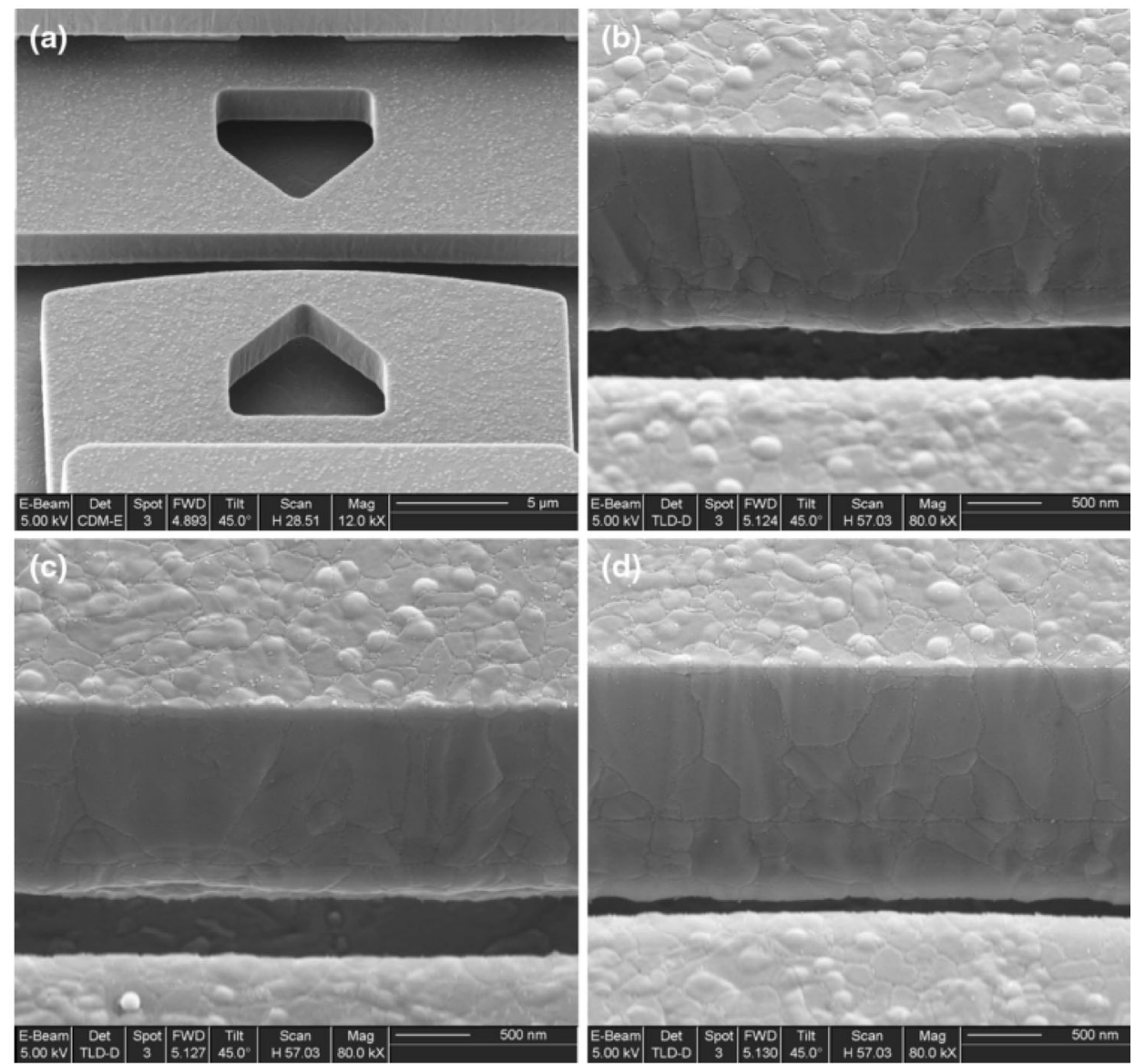

Fig. 16 (a) Low-magnification image of the post and shuttle of MEMS devices. (b)-(d) High-magnification SEM images of the post side of the contact for dynamic friction MEMS tests under a $500 \mathrm{nN}$ contact load after $10^{6}$ cycles in environments containing $50 \% P / P$ sat n-pentanol vapor and (b) $0 \% \mathrm{RH}$, (c) 15\% RH, and (d) 20\% RH. Reproduced with permission from Ref. [219]. Copyright Springer, 2014. 
MEMS devices with moving parts to be utilized in humid environment. Also, such studies highlight the importance of qualitatively and quantitatively studying the co-adsorption behavior of vapors and their effect on friction and wear.

\subsection{Mechanochemical synthesis of nano-lubricant films from vapor}

While adsorbed vapors can act as lubricants to mitigate friction and wear of sliding contacts, a continuous flow or supply of the lubricating vapors is required for effective lubrication. Insufficient or intermittent delivery of vapors to the contact area can result in failure [216]. Pentanol vapor, for example, was found to be a good lubricant for self-mated silica contact, a system very important for electronics applications. However, when the amount of vapor supplied to the contact area was inadequate, friction became chaotic and silicon was severely worn [216]. The worn areas contained hydrocarbon deposit with molecular weight much higher than that of pentanol. The deposit is called a tribo-polymer and is formed by a mechanochemical process catalyzed by the wear debris [216].

Mechanochemistry is a term that describes nonthermal chemical reactions occurring on solid surfaces solely due to mechanical processes like shear, repetitive impact, and tensile and compressive stresses. Mechanochemistry has limitations regarding product purification, energy consumption, and the lack of mechanistic understanding, but it is widely researched as a promising industrial synthesis technique [221]. In the field of tribology, understanding and preventing mechanochemical processes can be necessary to prevent failure in some systems where mechanochemical processes happen as a by-product of materials wear. Nonetheless, mechanochemical synthesis of lubricating species can be employed to improve the performance of other systems.

Mechanical processes allow chemical reactions to take place by increasing the surface area and exposing fresh surfaces through breaking solid surfaces into smaller particles, intimate mixing of reactants, introducing defects, providing frictional heating, and even ejecting energetic species like free radicals and plasma [221, 222]. Mechanical work can also directly facilitate chemical reactions by lowering their activation energies
[223]. The activation barrier for breaking covalent bonds was found to be a function of the applied mechanical load; large mechanical loads stretch covalent bonds, reducing their chemical potential energy [224].

In the case of self-mated silicon oxide surfaces mentioned earlier, the synthesis of tribo-polymer by mechanochemical polymerization of adsorbed pentanol vapor occurred as a result of wear. As the amount of adsorbed vapor was insufficient and failed to lubricate the sliding contact, the polymerization reaction was initiated. The fact that the tribo-polymer was found only within the contact area when the lubrication failed indicated that the polymerized material was not responsible for lubrication but rather a byproduct of the wear process [216]. It was suggested that the $\mathrm{Si}$ dangling bonds that formed during the wear process acted as a catalyst for polymer formation [216]. It was also found that the minimum vapor pressure of pentanol in the surrounding environment required for adequate lubrication increased as the applied load increased [216]. If the vapor pressure was lower than the minimum partial pressure required, wear took place and tribo-polymers formed.

In contrast, mechanochemistry can be used or designed to synthesize beneficial tribo-polymer films selectively at the sliding track by choosing proper precursor molecules as a vapor phase lubricant. This was demonstrated for allyl alcohol vapor lubrication for stainless steel surfaces [225]. For self-mated stainless steel sliding contact, allyl alcohol gave a friction coefficient of $\sim 0.2$ at a vapor partial pressure of $15 \%$ and higher, which is much lower than the friction of stainless steel in dry condition (higher than 1). It was also found that the adsorbed allyl alcohol molecules were polymerized only within the contact area during sliding [225]. No wear was found after sliding was stopped indicating that the tribo-products were not by-products of stainless steel wear. Unlike the wearinduced tribo-polymerization of adsorbed pentanol vapor on silicon oxide [216], the formation of allylalcohol tribo-product was attributed to polymerization of the unsaturated $\mathrm{C}=\mathrm{C}$ bond to form a polymerized alcohol [225]. When allyl alcohol vapor flow was stopped, the tribo-polymer was sufficient to lubricate the sliding contact. As shown in Fig. 17, the amount of the tribo-polymer formed during the initial 800 cycles 


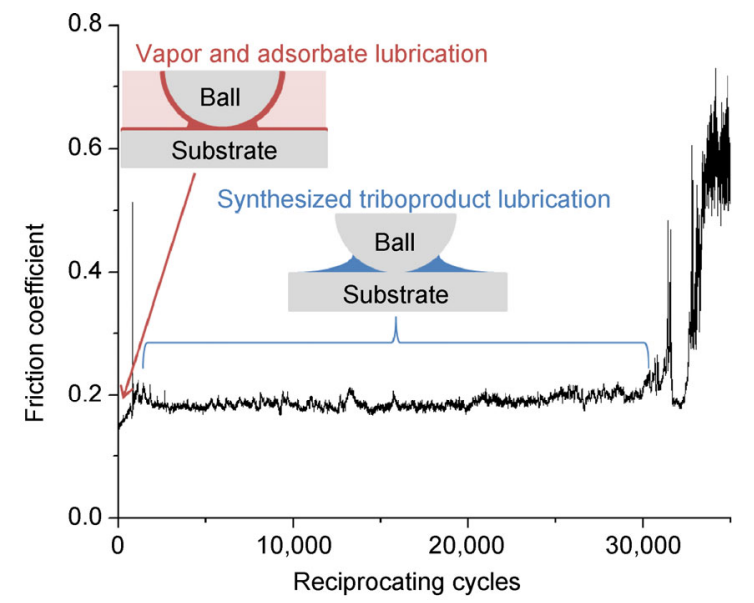

Fig. 17 Friction coefficient for stainless steel versus stainless steel to test the lubricity of the synthesized tribo-product in the absence of supplied allyl alcohol vapor. The first 800 cycles were conducted in an allyl alcohol vapor environment, after which the vapor flow was ceased and only dry nitrogen was supplied. The friction spike above 0.5 at the left side of the graph corresponds to the cessation of vapor flow. Reproduced with permission from Ref. [225]. Copyright The Royal Society of Chemistry, 2014.

of sliding in allyl alcohol environment lubricated the contact for over 30,000 cycles in dry conditions. The first spike corresponds the point when the allyl alcohol vapor flow was shut and the second one (followed by chaotic friction) is when the thin tribo-polymer film was exhausted and could no longer lubricate. Between the two spikes, the low stable friction is due to the tribo-polymer lubrication effect. Such tribo-products are essential to ensure lubrication in engineering applications that utilizes vapor phase lubrication where intermittent supply of vapors can occur.

\section{Summary}

Interfacial properties and tribological behaviors of materials are extremely complicated in the ambient condition due to the high reactivity of the molecules impinging from the surrounding environment. Nearly all materials undergo oxidation, structural changes, or tribochemical reaction in the ambient environment. This can occur even in the absence of oxygen if water vapor dissociates on the surface or if organic vapors adsorb on it.

The oxidized metal surfaces may form lubricating interfacial layers or detrimental third body abrasives depending on material properties. Similarly, when ceramics are exposed to water vapor, tribochemical reactions occur resulting in the formation of wear susceptible oxide layers and abrasive debris. On the contrary, silicon nitrides and carbides, as well as boron and titanium containing ceramics, have been shown to form silicon oxide layers at the interface that generally reduce wear during sliding. In glasses, oxidation of silicon can initiate stress corrosion and propagation of defects in the presence of water vapor, which is detrimental to the wear resistance of glasses. In carbon materials, oxidation due to the presence of adsorbed water can either be beneficial or unfavorable to the ultra-low friction behavior depending on the initial passivation of the carbon surface with hydrogen.

The structure of materials can also be greatly affected by the environment. The molecules adsorbed and reacted at the basal planes and edge sites of graphite, for instance, have a huge impact on the structure and defects in graphite. In glasses, ion leaching and ion exchange with protons or hydronium ions upon interaction with water molecules further complicates not only the surface, but also the bulk mechanical properties and structures of glasses. Another example of bulk changes due to environment is the absorption of vapors by polymeric materials. The dual behavior of polymers to adsorb and absorb vapor molecules leads to added complexity that is still poorly understood. The absorption of water or organic vapors can critically affect the mechanical properties of polymers through plasticization.

Although vapors are prone to react under tribological stress to induce unwanted changes or form undesired products, the adsorption and in some cases the tribochemical reaction of organic vapors can effectively lubricate systems with sliding contacts. Alcohol vapors are effective lubricants of self-mated silica surfaces and MEMS devices. Insufficient or intermittent delivery of vapor to such systems can, however, not only fail to lubricate, but also initiate undesired tribo-chemical reactions. Other tribo-products, in contrast, can ensure effective lubrication in applications where constant vapor delivery cannot be guaranteed.

\section{Acknowledgements}

The authors acknowledged financial supports from the National Science Foundation (Grant Nos. CMMI1000021, CMMI-1131128, and DMR-1207328). 
Open Access: This article is distributed under the terms of the Creative Commons Attribution License which permits any use, distribution, and reproduction in any medium, provided the original author(s) and source are credited.

\section{References}

[1] Campbell C T. Transition metal oxides: Extra thermodynamic stability as thin films. Phys Rev Lett 96 (6): 066106 (2006)

[2] Verdaguer A, Sacha G M, Bluhm H, Salmeron M. Molecular structure of water at interfaces: Wetting at the nanometer scale. Chem Rev 106(4): 1478-1510 (2006)

[3] Somorjai G A, Kliewer C. J. Reaction selectivity in heterogeneous catalysis. React Kinet Catal L 96 (2): 191-208 (2009)

[4] Li Y, Somorjai G A. Nanoscale advances in catalysis and energy applications. Nano Lett 10(7): 2289-2295 (2010)

[5] Corma A. From microporous to mesoporous molecular sieve materials and their use in catalysis. Chem Rev 97(6): 2373-2420 (1997)

[6] Ferey G. Hybrid porous solids: Past, present, future. Chem Soc Rev 37(1): 191-214 (2008)

[7] Bartholomew C H. Mechanisms of catalyst deactivation. Appl Catal A: Gen 212(1): 17-60 (2001)

[8] Azad A, Akbar S, Mhaisalkar S, Birkefeld L, Goto K. Solidstate gas sensors: A review. J Electrocheml Soc 139(12): 3690-3704 (1992)

[9] Homola J, Yee S S, Gauglitz G. Surface plasmon resonance sensors: Review. Sensor Actuat B: Chem 54(1-2): 3-15 (1999)

[10] Albert K J, Lewis N S, Schauer C L, Sotzing, G A, Stitzel S E, Vaid T P, Walt D R. Cross-reactive chemical sensor arrays. Chem Rev 100(7): 2595-2626 (2000)

[11] Barsan N, Koziej D, Weimar U. Metal oxide-based gas sensor research: How to? Sensor Actuat B: Chem 121(1): 18-35 (2007)

[12] Yamazoe N. Toward innovations of gas sensor technology. Sensor Actuat B: Chem 108(1): 2-14 (2005)

[13] Savage R H. Graphite lubrication. J Appl Phys 19(1): 1-10 (1948)

[14] Park S J, Kim J K, Lee K R, Ko D. H. Humidity dependence of the tribological behavior of diamond-like carbon films against steel ball. Diam Relat Mater 12(9): 1517-1523 (2003)

[15] Marino M J, Hsiao E, Bradley L C, Eryilmaz O L, Erdemir A, Kim S H. Is ultra-low friction needed to prevent wear of diamond-like carbon (DLC)? An alcohol vapor lubrication study for stainless steel/DLC interface. Tribol Lett 42(3): 285-291 (2011)
[16] Barthel A, Gregory M, Kim S. Humidity effects on friction and wear between dissimilar metals. Tribol Lett 48(3): 305313 (2012)

[17] Asay D, De Boer M, Kim S. Equilibrium vapor adsorption and capillary force: Exact Laplace-Young equation solution and circular approximation approaches. J Adh Sci Tech 24(15-16): 2363-2382 (2010)

[18] Asay D B, Hsiao E, Kim S H. Effects of adsorbate coverage and capillary on nano-asperity friction in atmosphere containing organic vapor. J Appl Phys 110(6): 064326 (2011)

[19] I-Ming F. A new approach in interpreting the four-ball wear results. Wear 5(4): 275-288 (1962)

[20] Fouvry S, Kapsa P, Vincent L. Quantification of fretting damage. Wear 200(1): 186-205 (1996)

[21] Feng I M, Uhlig H H. Fretting corrosion of mild steel in air and in nitrogen. $J$ Appl Mech 21(4): 395-400 (1954)

[22] Godfrey D, Bailey J. Early stages of fretting of copper, iron and steel. Lubr Engine 10: 155 (1954)

[23] Chowdhury M A, Helali M M. The effect of frequency of vibration and humidity on the coefficient of friction. Tribol Int 39(9): 958-962 (2006)

[24] Chowdhury M A, Helali M M. The effect of frequency of vibration and humidity on the wear rate. Wear 262(1-2): 198-203 (2007)

[25] Oh H-K, Yeon K-H, Yun Kim H. The influence of atmospheric humidity on the friction and wear of carbon steels. J Mater Process Tech 95(1): 10-16 (1999)

[26] Bregliozzi G, Di Schino A, Kenny J, Haefke H. The influence of atmospheric humidity and grain size on the friction and wear of AISI 304 austenitic stainless steel. Mater Lett 57(29): 4505-4508 (2003)

[27] Bregliozzi G, Ahmed S-U, Di Schino A, Kenny J, Haefke H. Friction and wear behavior of austenitic stainless steel: Influence of atmospheric humidity, load range, and grain size. Tribol Lett 17(4): 697-704 (2004)

[28] Endo K, Goto H. Effects of environment on fretting fatigue. Wear 48(2): 347-367 (1978)

[29] Junyan L, Huanpeng L, Rongdi H, Yang W. The study on lubrication action with water vapor as coolant and lubricant in cutting ANSI 304 stainless steel. Int J Mach Tool Manu 50(3): 260-269 (2010)

[30] Klaffke D. On the repeatability of friction and wear results and on the influence of humidity in oscillating sliding tests of steel-steel pairings. Wear 189(1): 117-121 (1995)

[31] de Baets P, Kalacska G, Strijckmans K, Van de Velde F, Van Peteghem A P. Experimental study by means of thin layer activation of the humidity influence on the fretting wear of steel surfaces. Wear 216(2): 131-137 (1998) 
[32] Barthel A, Kim S. Surface chemistry dependence of water adsorption on solid substrates in humid ambient and humidity effects on wear of copper and glass surfaces. Tribol-Mater, Surf Interf 7: 63-68 (2012)

[33] Cai Z, Zhu M, Shen H, Zhou Z, Jin X. Torsional fretting wear behaviour of 7075 aluminium alloy in various relative humidity environments. Wear 267(1): 330-339 (2009)

[34] Kim H J, Karthikeyan S, Rigney D. The structure and composition of aluminum wear debris generated by unlubricated sliding in different environments. Wear 263(1): 849-857 (2007)

[35] Yen B K. The effect of humidity on friction and wear of an aluminium-silicon eutectic alloy. J Mater Sci 32(3): 821-828 (1997)

[36] Yen B, Ishihara T. Effect of humidity on friction and wear of $\mathrm{Al}-\mathrm{Si}$ eutectic alloy and $\mathrm{Al}-\mathrm{Si}$ alloy-graphite composites. Wear 198(1): 169-175 (1996)

[37] Goto H, Ashida M, Endo K. The influence of oxygen and water vapour on the friction and wear of an aluminium alloy under fretting conditions. Wear 116(2): 141-155 (1987)

[38] Liew W Y H. Effect of relative humidity on the unlubricated wear of metals. Wear 260(7-8): 720-727 (2006)

[39] Imada Y, Nakajima K. Effect of humidity on the friction and wear properties of Sn. J Tribol 117(4): 737-741 (1995)

[40] Park Y W, Sankara Narayanan T, Lee K Y. Fretting corrosion of tin-plated contacts. Tribol Int 41(7): 616-628 (2008)

[41] Goto H, Buckley D. The influence of water vapour in air on the friction behaviour of pure metals during fretting. Tribol Int 18(4): 237-245 (1985)

[42] Goto H, Ashida M. Friction and wear of 6040 brass during fretting corrosion under various environmental conditions. Tribol Int 21(4): 183-190 (1988)

[43] Andersson K, Ketteler G, Bluhm H, Yamamoto S, Ogasawara H, Pettersson L G, Salmeron M, Nilsson A. Bridging the pressure gap in water and hydroxyl chemistry on metal surfaces: The $\mathrm{Cu}$ (110) case. J Phys Chem C 111(39): 14493-14499 (2007)

[44] Deng X, Herranz T, Weis C, Bluhm H, Salmeron M. Adsorption of water on $\mathrm{Cu}_{2} \mathrm{O}$ and $\mathrm{Al}_{2} \mathrm{O}_{3}$ thin films. $J$ Phys Chem C 112(26): 9668-9672 (2008)

[45] Deng X, Verdaguer A, Herranz T, Weis C, Bluhm H, Salmeron M. Surface chemistry of $\mathrm{Cu}$ in the presence of $\mathrm{CO}_{2}$ and $\mathrm{H}_{2} \mathrm{O}$. Langmuir 24(17): 9474-9478 (2008)

[46] Furlong O, Li Z, Gao F, Tysoe W T. Surface and tribological chemistry of water and carbon dioxide on copper surfaces. Tribol Lett 31(3): 167-176 (2008)

[47] Louthan M R, Rawl D E, Caskey G R, Donovan J A. Hydrogen embrittlement of metals. Mater Sci Eng 10(6): 357-368 (1972)
[48] Hermance H, Egan T. Organic deposits on precious metal contacts. Bell Syst Tech J 37(3): 739-776 (1958)

[49] Chen L, Lee H, Guo Z J, McGruer N E, Gilbert K W, Mall S, Leedy K D, Adams G G. Contact resistance study of noble metals and alloy films using a scanning probe microscope test station. J Appl Phys 102(7): 174910 (2007)

[50] Wu X, Kobayashi N, Nanao H, Mori S. Adsorption and reaction of cyclohexene and 1-hexene on nascent gold surface formed by friction. Tribol Lett 18(2): 239-244 (2005)

[51] Buckley D H. Influence of chemisorbed films of various gases on adhesion and friction of tungsten. J Appl Phys 39(9): 4224-4233 (1968)

[52] Williams J, Tabor D. The role of lubricants in machining. Wear 43(3): 275-292 (1977)

[53] Kotvis P V, Huezo L A, Tysoe W T. Surface-chemistry of methylene-chloride on iron-A model for chlorinated- hydrocarbon lubricant additives. Langmuir 9(2): 467-47 (1993)

[54] Kotvis P V, Lara J, Surerus K, Tysoe W T. The nature of the lubricating films formed by carbon tetrachloride under conditions of extreme pressure. Wear 201(1-2): 10-14 (1996)

[55] Graham E, Klaus E. Lubrication from the vapor phase at high temperatures. ASLE Trans 29(2): 229-234 (1986)

[56] Graham E, Nesarikar A, Forster N, Givan G. Vapor phase lubrication of high-temperature bearings. STLE Lubr Eng 49(9): 713-718 (1993)

[57] McFadden C, Gellman A. Metallic friction: The effect of molecular adsorbates. Surf Sci 409(2): 171-182 (1998)

[58] McFadden C F, Gellman A J. Ultrahigh vacuum boundary lubrication of the $\mathrm{Cu}-\mathrm{Cu}$ interface by 2, 2, 2-trifluoroethanol. Langmuir 11(1): 273-280 (1995)

[59] Philippon D, De Barros-Bouchet M I, Lerasle O, Le Mogne T, Martin J M. Experimental simulation of tribochemical reactions between borates esters and steel surface. Tribol Lett 41(1): 73-82 (2011)

[60] Fischer T, Tomizawa H. Interaction of tribochemistry and microfracture in the friction and wear of silicon nitride. Wear 105(1): 29-45 (1985)

[61] Fischer T, Mullins W. Chemical aspects of ceramic tribology. J Phys Chem 96(14): 5690-5701 (1992)

[62] Fischer T. Tribochemistry. Annu Rev Mater Sci 18(1): 303-323 (1988)

[63] Dante R C, Kajdas C. A review and a fundamental theory of silicon nitride tribochemistry. Wear 288: 27-38 (2012)

[64] Westwood A, Latanision R. Environment-sensitive machining behavior of nonmetals. NBS Special Publication 348: 141154 (1972)

[65] Ishigaki H, Kawaguchi I, Iwasa M, Toibana Y. Friction and wear of hot pressed silicon nitride and other ceramics. J Tribol 108(4): 514-521 (1986) 
[66] Komvopoulos K, Li H. The effect of tribofilm formation and humidity on the friction and wear properties of ceramic materials. J Tribol Transe ASME 114(1): 131-140 (1992)

[67] Kapsa P, Enomoto Y. Sliding damage on hot-pressed and sintered silicon nitride caused by a diamond tip under controlled humidity. Wear 127(1): 65-83 (1988)

[68] Sasaki S. The effects of the surrounding atmosphere on the friction and wear of alumina, zirconia, silicon carbide and silicon nitride. Wear 134(1): 185-200 (1989)

[69] Lee K H, Kim K W. Effects of humidity and sliding speed on the wear properties of $\mathrm{Si}_{3} \mathrm{~N}_{4}$ ceramics. Mater Sci Eng: $A$ 186(1): 185-191 (1994)

[70] Ishigaki H, Nagata R, Iwasa M. Effect of adsorbed water on friction of hot-pressed silicon nitride and silicon carbide at slow speed sliding. Wear 121(1): 107-116 (1988)

[71] Xu J, Kato K. The effect of water vapor on the agglomeration of wear particles of ceramics. Wear 202(2): 165-171 (1997)

[72] Saito T, Imada Y, Honda F. An analytical observation of the tribochemical reaction of silicon nitride sliding with low friction in aqueous solutions. Wear 205(1): 153-159 (1997)

[73] Gee M, Butterfield D. The combined effect of speed and humidity on the wear and friction of silicon nitride. Wear 162: 234-245 (1993)

[74] Murthy V, Kobayashi H, Tsurekawa S, Tamari N, Watanabe $\mathrm{T}$, Kato K. Influence of humidity and doping elements on the friction and wear of $\mathrm{SiC}$ in unlubricated sliding. Tribol Int 37(5): 353-364 (2004)

[75] Gates R S, Hsu S M. Tribochemistry between water and $\mathrm{Si}_{3} \mathrm{~N}_{4}$ and $\mathrm{SiC}$ : Induction time analysis. Tribol Lett 17(3): 399-407 (2004)

[76] Erdemir A, Bindal C, Zuiker C, Savrun E. Tribology of naturally occurring boric acid films on boron carbide. Surf Coat Tech 86: 507-510 (1996)

[77] Erdemir A, Bindal C, Fenske G. Formation of ultralow friction surface films on boron carbide. Appl Phys Lett 68(12): 1637-1639 (1996)

[78] Cuong P D, Ahn H-S, Yoon E-S, Shin K-H. Effects of relative humidity on tribological properties of boron carbide coating against steel. Surf Coat Tech 201(7): 4230-4235 (2006)

[79] Barthel A J, Luo J, Kim S H. Origin of ultra-low friction of boric acid: Role of vapor adsorption. Tribol Lett in press, DOI 10.1007/s11249-015-0512-7 (2015)

[80] de Wit E, Froyen L, Celis J-P. The crystallization of amorphous debris on titanium nitride coatings influenced by sliding wear conditions. Wear 221(2): 124-133 (1998)

[81] Mohrbacher H, Blanpain B, Celis J-P, Roos J. The influence of humidity on the fretting behaviour of PVD TiN coatings. Wear 180(1): 43-52 (1995)
[82] Argibay N, Keith J H, Krick B A, Hahn D, Bourne G R, Sawyer W G. High-temperature vapor phase lubrication using carbonaceous gases. Tribol Lett 40(1): 3-9 (2010)

[83] Liu W, Klaus E, Duda J. Wear behaviour of steel-on- $\mathrm{Si}_{3} \mathrm{~N}_{4}$ and $\mathrm{Si}_{3} \mathrm{~N}_{4}$ on $\mathrm{Si}_{3} \mathrm{~N}_{4}$ systems with vapor phase lubrication of oleic acid and TCP. Wear 214(2): 207-211 (1998)

[84] Charles R J. Static fatigue of glass. I. J Appl Phys 29(11): 1549-1553 (1958)

[85] Cotinaud M, Bonniau P, Bunsell A R. The effect of water absorption on the electrical properties of glass-fibre reinforced epoxy composites. J Mater Sci 17(3): 867-877 (1982)

[86] Han W-T, Tomozawa M. Effect of residual water in silica glass on static fatigue. J Non-cryst Solids 127(1): 97-104 (1991)

[87] Tomozawa M. Fracture of glasses. Annu Rev Mater Sci 26(1): 43-74 (1996)

[88] Wiederhorn S M. Influence of water vapor on crack propagation in soda-lime glass. $J$ Am Ceram Soc 50(8): 407-414 (1967)

[89] Wiederhorn S M, Bolz L H. Stress corrosion and static fatigue of glass. J Am Ceram Soc 53(10): 543-548 (1970)

[90] Chuang I S, Maciel G E. A Detailed model of local structure and silanol hydrogen bonding of silica gel surfaces. $J$ Phys Chem B 101(16): 3052-3064 (1997)

[91] Hair M L, Hertl W. Adsorption on hydroxylated silica surfaces. J Phys Chem 73(12): 4269-4276 (1969)

[92] Zhuravlev L T. The surface chemistry of amorphous silica. Zhuravlev model. Colloid Surface A: Physicochem Eng Aspects 173(1-3): 1-38 (2000)

[93] Asay D B, Kim S H. Evolution of the adsorbed water layer structure on silicon oxide at room temperature. $J$ Phys Chem B 109(35): 16760-16763 (2005)

[94] Davydov V Y, Kiselev A, Zhuravlev L. Study of the surface and bulk hydroxyl groups of silica by infra-red spectra and D2O-exchange. Trans Faraday Soc 60: 2254-2264 (1964)

[95] Kratochvíla J, Salajka Z, Kazda A, Kadlc Z, Souček J, Gheorghiu, M. Determination of hydroxyl groups and free water on silica gel in the near infrared region. $J$ Non-cryst Solids 116(1): 93-99 (1990)

[96] Ek S, Root A, Peussa M, Niinistö L. Determination of the hydroxyl group content in silica by thermogravimetry and a comparison with $1 \mathrm{H}$ MAS NMR results. Thermochimica Acta 379(1-2): 201-212 (2001)

[97] Dinh L N, Balooch M, LeMay J D. $\mathrm{H}_{2} \mathrm{O}$ outgassing properties of fumed and precipitated silica particles by temperatureprogrammed desorption. J Colloid Interf Sci 230(2): 432-440 (2000)

[98] Varshneya A K. Fundamentals of Inorganic Glasses. Academic Press: Boston, 1994.

[99] Scholze H. Chemical durability of glasses. J Non-cryst Solids 52(1-3): 91-103 (1982) 
[100] Abrams M B, Green D J, Jill Glass S. Fracture behavior of engineered stress profile soda lime silicate glass. J Non-cryst Solids 321(1-2): 10-19 (2003)

[101] Kistler S S. Stresses in glass produced by nonuniform exchange of monovalent ions. J Am Ceram Soc 45(2): 59-68 (1962)

[102] Lee Y-K, Peng Y L, Tomozawa M. IR reflection spectroscopy of a soda-lime glass surface during ion-exchange. J Non-cryst Solids 222: 125-130 (1997)

[103] Nordberg M E, Mochel E L, Garfinkel H M, Olcott J S. Strengthening by ion exchange. J Am Ceram Soc 47(5): 215-219 (1964)

[104] Varshneya A K. The physics of chemical strengthening of glass: Room for a new view. J Non-cryst Solids 356 (44-49): 2289-2294 (2010)

[105] Lanford W A, Davis K, Lamarche P, Laursen T, Groleau R, Doremus R H. Hydration of soda-lime glass. J Non-cryst Solids 33(2): 249-266 (1979)

[106] Schnatter K H, Doremus R H, Lanford W A. Hydrogen analysis of soda-lime silicate glass. J Non-cryst Solids 102(1-3): 11-18 (1988)

[107] Tomozawa M, Cherniak D J, Lezzi P J. Hydrogen-toalkali ratio in hydrated alkali aluminosilicate glass surfaces. J Non-cryst Solids 358(24): 3546-3550 (2012)

[108] Schnatter K H, Doremus R H, Lanford W A. Hydrogen analysis of soda-lime silicate glass. J Non-cryst Solids 102(1): 11-18 (1988)

[109] Barthel A J, Al-Azizi A, Surdyka N D, Kim S H. Effects of gas or vapor adsorption on adhesion, friction, and wear of solid interfaces. Langmuir 30(11): 2977-2992 (2013)

[110] Bradley L C, Dilworth Z R, Barnette A L, Hsiao E, Barthel A J, Pantano C G, Kim S H. Hydronium ions in soda-lime silicate glass surfaces. J Am Ceram Soc 96(2): 458-463 (2013)

[111] Freiman S W, Wiederhorn S M, Mecholsky Jr J J. Environmentally enhanced fracture of glass: A historical perspective. J Am Ceram Soc 92(7): 1371-1382 (2009)

[112] Griffith A A. The phenomena of rupture and flow in solids. Philos T R Soc A 221: 163-197 (1921)

[113] Orowan E, Orowan E. The fatigue of glass under stress. Nature 154(3906): 341-343 (1944)

[114] Zhang Y-A, Tao J, Chen X, Liu B. Mixed-pattern cracking in silica during stress corrosion: A reactive molecular dynamics simulation. Comp Mater Sci 82: 237-243 (2014)

[115] Ahn Y, Farris T N, Chandrasekar S. Sliding microindentation fracture of brittle materials: Role of elastic stress fields. Mech Mater 29(3-4): 143-152 (1998)

[116] Le Houérou V, Sanglebœuf J C, Rouxel T. Scratchability of soda-lime silica (SLS) glasses: Dynamic fracture analysis. Key Eng Mater 290: 31-38 (2005)

[117] Le Houérou V, Sangleboeuf J C, Dériano S, Rouxel T, Duisit G. Surface damage of soda-lime-silica glasses: Indentation scratch behavior. J Non-cryst Solids 316(1): 54-63 (2003)

[118] Yu J, Kim S H, Yu B, Qian L, Zhou Z. Role of tribochemistry in nanowear of single-crystalline silicon. ACS Appl Mater \& Interf 4(3): 1585-1593 (2012)

[119] Marchand D, Chen L, Meng Y, Qian L, Kim S. Effects of vapor environment and counter-surface chemistry on tribochemical wear of silicon wafers. Tribol Lett 53(1): 365-372 (2014)

[120] Chen L, Kim S, Wang X, Qian L. Running-in process of $\mathrm{Si}-\mathrm{SiO}_{x} / \mathrm{SiO}_{2}$ pair at nanoscale-Sharp drops in friction and wear rate during initial cycles. Friction 1(1): 81-91 (2013)

[121] Wang X D, Song C F, Yu B J, Chen L, Qian L M. Nanowear behaviour of monocrystalline silicon against $\mathrm{SiO}_{2}$ tip in water. Wear 298-299: 80-86 (2013)

[122] Wang X D, Yu J X, Chen L, Qian L M, Zhou Z R. Effects of water and oxygen on the tribochemical wear of monocrystalline $\mathrm{Si}(100)$ against $\mathrm{SiO}_{2}$ sphere by simulating the contact conditions in MEMS. Wear 271(9-10): 16811688 (2011)

[123] Vigil G, Xu Z, Steinberg S, Israelachvili J. Interactions of silica surfaces. J Colloid Interf Sci 165(2): 367-385 (1994)

[124] He H, Qian L, Pantano C G, Kim S H. Mechanochemical wear of soda lime silica glass in humid environments. $J \mathrm{Am}$ Ceram Soc 97(7): 2061-2068 (2014)

[125] Surdyka N, Pantano C, Kim S. Environmental effects on initiation and propagation of surface defects on silicate glasses: Scratch and fracture toughness study. Appl Phys A 116(2): 519-528 (2014)

[126] Asay D B, Kim S H. Molar volume and adsorption isotherm dependence of capillary forces in nanoasperity contacts. Langmuir 23(24): 12174-12178 (2007)

[127] Barnette A L, Asay D B, Janik M J, Kim S H. Adsorption isotherm and orientation of alcohols on hydrophilic sio $_{2}$ under ambient conditions. J Phys Chem C 113(24): 1063210641 (2009)

[128] Barnette A L, Asay D B, Kim D, Guyer B D, Lim H, Janik M J, Kim S H. Experimental and density functional theory study of the tribochemical wear behavior of $\mathrm{SiO}_{2}$ in humid and alcohol vapor environments. Langmuir 25(22): 1305213061 (2009)

[129] Lancaster J K. A review of the influence of environmental humidity and water on friction, lubrication and wear. Tribol 
Int 23(6): 371-389 (1990)

[130] Michalske T A, Bunker B C, Freiman S W. Stress corrosion of ionic and mixed ionic/covalent solids. J Am Ceram Soc 69(10): 721-724 (1986)

[131] Wiederhorn S M, Fuller E R, Thomson R. Micromechanisms of crack growth in ceramics and glasses in corrosive environments. Metal Sci 14(8-9): 450-458 (1980)

[132] Ajayi O O, Ludema K C. Surface damage of structural ceramics: Implications for wear modeling. Wear 124(2): 237-257 (1988)

[133] Jahanmir S, Dong X. Mechanism of mild to severe wear transition in alpha-alumina. J Tribol 114(3): 403-411 (1992)

[134] Mori S, Cong P, Shinden Y, Nanao H. Tribochemical reactions and lubricating effects of fluorinated methanes for $\mathrm{Al}_{2} \mathrm{O}_{3}$ ceramic. Tribol Lett 17(1): 83-89 (2004)

[135] Olofsson J, Johansson S, Jacobson S. Influence from humidity on the alumina friction drive system of an ultrasonic motor. Tribol Int 42(10): 1467-1477 (2009)

[136] Basu B, Vitchev R G, Vleugels J, Celis J P, Van Der Biest $O$. Influence of humidity on the fretting wear of selfmated tetragonal zirconia ceramics. Acta Materialia 48(10): 2461-2471 (2000)

[137] Fischer T E, Anderson M P, Jahanmir S, Salher R. Friction and wear of tough and brittle zirconia in nitrogen, air, water, hexadecane and hexadecane containing stearic acid. Wear 124(2): 133-148 (1988)

[138] Hannink R H J, Murray M J, Scott H G. Friction and wear of partially stabilized zirconia: Basic science and practical applications. Wear 100(1-3): 355-366 (1984)

[139] Zum Gahr K H. Sliding wear of ceramic-ceramic, ceramicsteel and steel-steel pairs in lubricated and unlubricated contact. Wear 133(1): 1-22 (1989)

[140] Wang Y, Hsu S M. The effects of operating parameters and environment on the wear and wear transition of alumina. Wear 195(1-2): 90-99 (1996)

[141] Shobert E I. Carbon, graphite, and contacts. Parts, Hybrids, and Packaging, IEEE Transactions on 12(1): 62-74 (1976)

[142] Savage R. Graphite lubrication. J Appl Phys 19(1): 1-10 (1947)

[143] Savage R H, Schaefer D L. Vapor lubrication of graphite sliding contacts. J Appl Phys 27(2): 136-138 (1956)

[144] Robert H. Physically and chemically adsorbed films in the lubrication of graphite sliding contacts. Ann New York Acad Sci 53(4): 862-869 (1951)

[145] Lin L-Y, Kim D-E, Kim W-K, Jun S-C. Friction and wear characteristics of multi-layer graphene films investigated by atomic force microscopy. Surf Coat Tech 205(20): 4864-4869 (2011)
[146] Bryant P J, Gutshall P L, Taylor L H. A study of mechanisms of graphite friction and wear. Wear 7(1): 118-126 (1964)

[147] Yen B K, Schwickert B E, Toney M F. Origin of lowfriction behavior in graphite investigated by surface $\mathrm{x}$-ray diffraction. Appl Phys Lett 84(23): 4702-4704 (2004)

[148] Deacon R F, Goodman J F. Lubrication by lamellar solids. Proc $R$ Soc Lond A Math Phys Sci 243(1235): 464-482 (1958)

[149] Yen B K. Influence of water vapor and oxygen on the tribology of carbon materials with $\mathrm{sp}^{2}$ valence configuration. Wear 192(1-2): 208-215 (1996)

[150] Ong T S, Yang H. Effect of atmosphere on the mechanical milling of natural graphite. Carbon 38(15): 2077-2085 (2000)

[151] Vinogradov N A, Schulte K, Ng M L, Mikkelsen A, Lundgren E, Mårtensson N, Preobrajenski A B. Impact of atomic oxygen on the structure of graphene formed on Ir(111) and Pt(111). J Phys Chem C 115(19): 9568-9577 (2011)

[152] Feng X, Maier S, Salmeron M. Water splits epitaxial graphene and intercalates. J Am Chem Soc 134(12): 5662 5668 (2012)

[153] Liao Q, Zhang H J, Wu K, Li H Y, Bao S N, He P. Oxidation of graphene on $\mathrm{Ru}(001)$ studied by scanning tunneling microscopy. Appl Surf Sci 257(1): 82-86 (2010)

[154] Marino M. Is ultra-low friction needed to prevent wear of diamond-like carbon (DLC)? An alcohol vapor lubrication study for stainless steel/dlc interface. Tribol Lett 42: 285 $291(2011)$

[155] Andersson J, Erck R A, Erdemir A. Friction of diamondlike carbon films in different atmospheres. Wear 254(11): 1070-1075 (2003)

[156] Erdemir A. Synthesis of superlow-friction carbon films from highly hydrogenated methane plasmas. Surf Coat Technol 133-134: 448-454 (2000)

[157] Erdemir A. Genesis of superlow friction and wear in diamondlike carbon films. Tribol Int 37(11-12): 1005-1012 (2004)

[158] Donnet C. Tribochemistry of diamond-like carbon coatings in various environments. Surf Coat Tech 68: 626-631 (1994)

[159] Yang M, Marino M J, Bojan V J, Eryilmaz O L, Erdemir A, Kim S H. Quantification of oxygenated species on a diamond-like carbon (DLC) surface. Appl Surf Sci 257(17): 7633-7638 (2011)

[160] Donnet C. The role of hydrogen on the friction mechanism of diamond-like carbon films. Tribol Lett 9(3): 137-142 (2001)

[161] Fontaine J, Belin M, Le Mogne T, Grill A. How to restore 
superlow friction of DLC: The healing effect of hydrogen gas. Tribol Int 37(11-12): 869-877 (2004)

[162] Eryilmaz O L, Erdemir A. On the hydrogen lubrication mechanism(s) of DLC films: An imaging TOF-SIMS study. Surf Coat Tech 203(5-7): 750-755 (2008)

[163] Erdemir A, Eryilmaz, O. L.; Kim, S. H. Effect of tribochemistry on lubricity of DLC films in hydrogen. Surf Coat Tech 257: 241-246 (2014)

[164] Piotrowski P L, Cannara R J, Gao G T, Urban J J, Carpick R W, Harrison J A. Atomistic factors governing adhesion between diamond, amorphous carbon and model diamond nanocomposite surfaces. $J$ Adh Sci Tech 24(15-16): 24712498 (2010)

[165] Schall J D, Gao G T, Harrison J A. Effects of adhesion and transfer film formation on the tribology of self-mated DLC contacts. J Physl Chem C 114(12): 5321-5330 (2010)

[166] Harrison J. Atomistic simulations of the nanotribology of carbon based materials: Establishing links between structure, chemistry, and performance. In NSF - CMMI conference, Boston, USA, 2012.

[167] Donnet C, Belin M, Augé J C, Martin J M, Grill A, Patel V. Tribochemistry of diamond-like carbon coatings in various environments. Surf Coat Tech 68-69: 626-631 (1994)

[168] Venkatraman C, Brodbeck C, Lei R. Tribological properties of diamond-like nanocomposite coatings at high temperatures. Surf Coat Tech 115(2-3): 215-221 (1999)

[169] Donnet C, Le Mogne T, Ponsonnet L, Belin M, Grill A, Patel V, Jahnes $\mathrm{C}$. The respective role of oxygen and water vapor on the tribology of hydrogenated diamond-like carbon coatings. Tribol Lett 4(3-4): 259-265 (1998)

[170] Erdemir A, Switala M, Wei R, Wilbur P. A tribological investigation of the graphite-to-diamond-like behavior of amorphous carbon films ion beam deposited on ceramic substrates. Surf Coat Tech 50(1): 17-23 (1991)

[171] Koskinen J, Ronkainen H, Varjus S, Muukkonen T, Holmberg K, Sajavaara T. Low friction ta-C films with hydrogen reservoirs. Diam Relat Mater 10(3-7): 1030-1035 (2001)

[172] Voevodin A A, Donley M S, Zabinski J S. Pulsed laser deposition of diamond-like carbon wear protective coatings: A review. Surf Coat Tech 92(1-2): 42-49 (1997)

[173] Harris S J, Weiner A M, Meng W-J. Tribology of metalcontaining diamond-like carbon coatings. Wear 211(2): 208-217 (1997)

[174] Kim H I, Lince J R, Eryilmaz O L, Erdemir A. Environmental effects on the friction of hydrogenated DLC films. Tribol Lett 21(1): 51-56 (2006)

[175] Eryilmaz O L, Erdemir A. Surface analytical investigation of nearly-frictionless carbon films after tests in dry and humid nitrogen. Surf Coat Tech 201(16-17): 7401-7407 (2007)

[176] Andersson J, Erck R A, Erdemir A. Frictional behavior of diamondlike carbon films in vacuum and under varying water vapor pressure. Surf Coat Tech 163-164: 535-540 (2003)

[177] Carpick R W, Flater E E, Sridharan K. The effect of surface chemistry and structure on nano-scale adhesion and friction. Polym Mater: Sci Eng 90: 197-198 (2004)

[178] Li H, Xu T, Wang C, Chen J, Zhou H, Liu H. Humidity dependence on the friction and wear behavior of diamondlike carbon film in air and nitrogen environments. Diam Relat Mater 15(10): 1585-1592 (2006)

[179] Filik J, May P W, Pearce S R J, Wild R K, Hallam K R. XPS and laser Raman analysis of hydrogenated amorphous carbon films. Diam Relat Mater 12(3-7): 974-978 (2003)

[180] Cloutier M, Harnagea C, Hale P, Seddiki O, Rosei F, Mantovani D. Long-term stability of hydrogenated DLC coatings: Effects of aging on the structural, chemical and mechanical properties. Diam Relat Mater 48: 65-72 (2014)

[181] Tagawa M, Ikemura M, Nakayama Y, Ohmae N. Effect of water adsorption on microtribological properties of hydrogenated diamond-like carbon films. Tribol Lett 17(3): 575-580 (2004)

[182] Erdemir A, Donnet C. Tribology of diamond-like carbon films: Recent progress and future prospects. J Phys D-Appl Phys 39(18): R311-R327 (2006)

[183] Al-Azizi A A, Eryilmaz O, Erdemir A, Kim S H. Nanotexture for a wear-resistant and near-frictionless diamondlike carbon. Carbon 73: 403-412 (2014)

[184] Schall J D, Gao G, Harrison J A. Effects of adhesion and transfer film formation on the tribology of self-mated DLC contacts. J Phys Chem C 114(12): 5321-5330 (2009)

[185] Marino M J, Hsiao E, Chen Y S, Eryilmaz O L, Erdemir A, Kim S H. Understanding run-in behavior of diamond-like carbon friction and preventing diamond-like carbon wear in humid air. Langmuir 27(20): 12702-12708 (2011)

[186] Al-Azizi A A, Eryilmaz O, Erdemir A, Kim S H. Surface structure of hydrogenated diamond-like carbon: origin of run-in behavior prior to superlubricious interfacial shear. Langmuir 31: 1711-1721 (2015)

[187] Erdemir A. Superlubricity and wearless sliding in diamondlike carbon films. MRS Online Proceedings Library 697: 1-13 (2001)

[188] Konicek A R, Grierson D S, Gilbert P U P A, Sawyer W G, Sumant A V, Carpick R W. Origin of ultralow friction and wear in ultrananocrystalline diamond. Phys Rev Lett 100(23): 
$235502(2008)$

[189] Konicek A R, Grierson D S, Sumant A V, Friedmann T A, Sullivan J P, Gilbert P U P A, Sawyer W G, Carpick R W. Influence of surface passivation on the friction and wear behavior of ultrananocrystalline diamond and tetrahedral amorphous carbon thin films. Phys Rev B 85(15): 155448 (2012)

[190] Arce A, Fornasiero F, Rodríguez O, Radke C J, Prausnitz J M. Sorption and transport of water vapor in thin polymer films at $35^{\circ} \mathrm{C}$. Phys Chem Chem Phys 6(1): 103-108 (2004)

[191] Hong S, Barbari T, Sloan J. Multicomponent diffusion of methyl ethyl ketone and toluene in polyisobutylene from vapor sorption FTIR-ATR spectroscopy. J Polym Sci Part B: Polym Phys 36(2): 337-344 (1998)

[192] Jelinski L W, Dumais J J, Cholli A L, Ellis T S, Karasz F E. Nature of the water epoxy interaction. Macromolecules 18(6): 1091-1095 (1985)

[193] Nicolson P C, Vogt J. Soft contact lens polymers: an evolution. Biomaterials 22(24): 3273-3283 (2001)

[194] Hsiao E, Barnette A L, Bradley L C, Kim S H. Hydrophobic but hygroscopic polymer films-Identifying interfacial species and understanding water ingress behavior. ACS Appl Mater Interf 3(11): 4236-4241 (2011)

[195] Thwe M M, Liao K. Effects of environmental aging on the mechanical properties of bamboo-glass fiber reinforced polymer matrix hybrid composites. Compos Part A: Appl Sci Manuf 33(1): 43-52 (2002)

[196] Karmaker A C. Effect of water absorption on dimensional stability and impact energy of jute fibre reinforced polypropylene. J Mater Sci Lett 16(6): 462-464 (1997)

[197] Bledzki A K, Reihmane S, Gassan J. Properties and modification methods for vegetable fibers for natural fiber composites. J Appl Polym Sci 59(8): 1329-1336 (1996)

[198] Garoff N, Zauscher S. The influence of fatty acids and humidity on friction and adhesion of hydrophilic polymer surfaces. Langmuir 18(18): 6921-6927 (2002)

[199] Bahadur S. The development of transfer layers and their role in polymer tribology. Wear 245(1-2): 92-99 (2000)

[200] Chitsaz-Zadeh M, Eiss Jr N. Friction and wear of polyimide thin films. Wear 110(3): 359-368 (1986)

[201] Podestà A, Fantoni G, Milani P, Guida C, Volponi S. Nanotribological characterization of industrial polytetrafluorethylene-based coatings by atomic force microscopy. Thin solid film 419(1): 154-159 (2002)

[202] McNicol A, Dowson D, Davies M. The effect of humidity and electrical fields upon the wear of high density polyethylene and polytetrafluoroethylene. Wear 181: 603612 (1995)
[203] Eriksson M, Lundqvist A, Jacobson S. A study of the influence of humidity on the friction and squeal generation of automotive brake pads. Proc IMechE, Part D: J Aut Eng 215(3): 329-342 (2001)

[204] Krick B A, Ewin J J, Blackman G S, Junk C P, Gregory Sawyer W. Environmental dependence of ultra-low wear behavior of polytetrafluoroethylene (PTFE) and alumina composites suggests tribochemical mechanisms. Tribol Int 51: 42-46 (2012)

[205] Hiratsuka K I, Hosotani K. Effects of friction type and humidity on triboelectrification and triboluminescence among eight kinds of polymers. Tribol Int 55: 87-99 (2012)

[206] Kovalchenko A, Ajayi O, Erdemir A, Fenske G, Etsion I. The effect of laser texturing of steel surfaces and speed-load parameters on the transition of lubrication regime from boundary to hydrodynamic. Tribol Trans 47(2): 299-307 (2004)

[207] Etsion I. Improving tribological performance of mechanical components by laser surface texturing. Tribol Lett 17(4): 733-737 (2004)

[208] Jiang J, Arnell R D. The effect of substrate surface roughness on the wear of DLC coatings. Wear 239(1): 1-9 (2000)

[209] Pettersson U, Jacobson S. Friction and wear properties of micro textured DLC coated surfaces in boundary lubricated sliding. Tribol Lett 17(3): 553-559 (2004)

[210] Al-Azizi A A, Eryilmaz O, Erdemir A, Kim S H. Effects of nanoscale surface texture and lubricant molecular structure on boundary lubrication in liquid. Langmuir 29(44): 13419-13426 (2013)

[211] Barthel A J, Kim S H. Lubrication by physisorbed molecules in equilibrium with vapor at ambient condition: Effects of molecular structure and substrate chemistry. Langmuir 30(22): 6469-6478 (2014)

[212] Kim S H, Asay D B, Dugger M T. Nanotribology and MEMS. Nano Today 2(5): 22-29 (2007)

[213] Asay D B, Dugger M T, Ohlhausen J A, Kim S H. Macroto nanoscale wear prevention via molecular adsorption. Langmuir 24(1): 155-159 (2007)

[214] Asay D B, Dugger M T, Kim S H. In-situ vapor-phase lubrication of MEMS. Tribol Lett 29(1): 67-74 (2008)

[215] Asay D B, Dugger M T, Ohlhausen J A, Kim S H. Macroto nanoscale wear prevention via molecular adsorption. Langmuir 2008, 24 (1), 155-159.

[216] Barnette A L, Asay D B, Ohlhausen J A, Dugger M T, Kim S H. Tribochemical Polymerization of adsorbed n-pentanol on $\mathrm{SiO}_{2}$ during rubbing: When does it occur and is it responsible for effective vapor phase lubrication? Langmuir 26(21): 16299-16304 (2010) 
[217] Tanner D M, Walraven J A, Irwin L W, Dugger M T, Smith N F, Eaton W P, Miller W M, Miller S L. The effect of humidity on the reliability of a surface micromachined microengine. In Reliability Physics Symposium Proceedings, 37th Annual. 1999 IEEE International, 1999: 189-197.

[218] Sammoura F, Hancer M, Yang K. The effect of surface chemistry on MEMS stiction in an ultralow-humidity environment. J Microelectromech Syst 20(2): 522-526 (2011)

[219] Barnette A, Ohlhausen J A, Dugger M, Kim S. Humidity effects on in situ vapor phase lubrication with n-pentanol. Tribol Lett 55(1): 177-186 (2014)

[220] Barnette A L, Kim S H. Coadsorption of n-propanol and water on $\mathrm{SiO}_{2}$ : Study of thickness, composition, and structure of binary adsorbate layer using attenuated total reflection infrared (ATR-IR) and sum frequency generation (SFG) vibration spectroscopy. J Phys Chem C 116(18): 9909-9916 (2012)

[221] James S L, Adams C J, Bolm C, Braga D, Collier P, Friscic

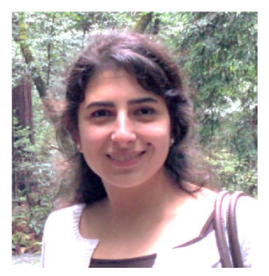

Ala ALAZIZI. She earned her BS degree in chemical engineering at the University of Jordan in 2010. Currently she is a PhD candidate

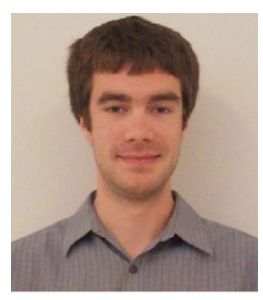

Anthony J. BARTHEL. He graduated from Iowa State University in 2009 with a BS degree in chemical

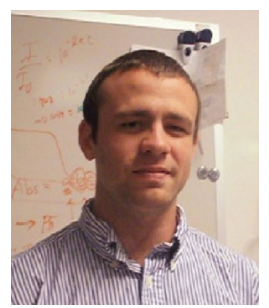

Nicholas D. SURDYKA. He graduated from University of California, Irvine in 2010 with a BS degree in chemical engineering
T, Grepioni F, Harris K D M, Hyett G, Jones W, Krebs A, Mack J, Maini L, Orpen A G, Parkin I P, Shearouse W C, Steed J W, Waddell D C. Mechanochemistry: Opportunities for new and cleaner synthesis. Chem Soc Rev 41(1): 413447 (2012)

[222] Nakayama K, Martin J-M. Tribochemical reactions at and in the vicinity of a sliding contact. Wear 261(3-4): 235-240 (2006)

[223] Beyer M K. The mechanical strength of a covalent bond calculated by density functional theory. $J$ Chem Phys 112(17): 7307-7312 (2000)

[224] Kaupp G. Mechanochemistry: The varied applications of mechanical bond-breaking. Crystengcomm 11(3): 388-403 (2009)

[225] Barthel A J, Combs D R, Kim S H. Synthesis of polymeric lubricating films directly at the sliding interface via mechanochemical reactions of allyl alcohols adsorbed from the vapor phase. RSC Adv 4(50): 26081-26086 (2014)

at the Pennsylvania State University studying the interfacial behavior of amorphous carbon surfaces (CMMI-1131128).

engineering. He is currently studying the environmental effects and frictional polymer formation at metal contacts (CMMI-1000021).

major and materials science and engineering minor. While he was at the Pennsylvania State University, he investigated the interfacial reactions of water at multicomponent glass surfaces (DMR-1207328). 


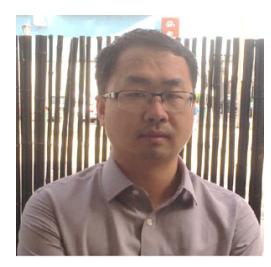

Jiawei LUO. He earned his BS degree in chemical engineering from Dalian University of Technology in
China. He is now studying the relationship between surface structure and mechanical properties of glass (DMR-1207328).

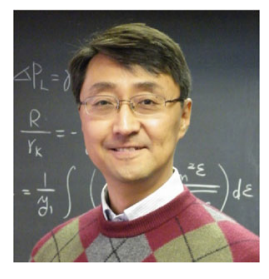

Seong H. KIM. He joined the faculty of Chemical Engineering in 2001 after completing a Ph.D. study in chemistry from Northwestern University and a post-doctoral research at University of California, Berkeley. He earned his BS and MS degrees in chemistry from Yonsei University, Korea. The main theme of his research lies in surface science and nano-engineering, especially applying surface science fundamentals to important interfacial problems involved in tribology and lubrication, nanomanufacturing, and surface engineering. Recently, his group extended the application of surface characterization methods to structural analysis of cellulose in biomass. 